\title{
IMPACT OF MARINE EXTRACTS APPLICATIONS ON CV. SYRAH GRAPE (VITIS \\ VINIFERA L.) YIELD COMPONENTS, HARVEST JUICE QUALITY PARAMETERS, AND NUTRIENT UPTAKE
}

\author{
A Thesis \\ presented to \\ the Faculty of California Polytechnic State University, \\ San Luis Obispo
}

\author{
In Partial Fulfillment \\ of the Requirements for the Degree \\ Master of Science in Agriculture, with a specialization in Crop Science \\ by \\ Jonathan Martin \\ March 2012
}


(C) 2012

Jonathan W. Martin

ALL RIGHTS RESERVED 


\section{COMMITTEE MEMBERSHIP}

TITLE: $\quad$ Impact of marine extracts applications on cv. Syrah grape (Vitis

vinifera L.) yield components, harvest juice quality parameters, and nutrient uptake

AUTHOR: Jonathan W. Martin

DATE SUBMITTED: $\quad$ February $17^{\text {th }}, 2012$

COMMITTEE CHAIR: $\quad$ Lauren Garner, Ph.D.

COMMITTEE MEMBER: W. Keith Patterson, Ph.D.

COMMITTEE MEMBER: Terry Smith, Ph.D. 


\title{
ABSTRACT \\ Impact of marine extracts applications on cv. Syrah grape (Vitis vinifera L.) yield components, harvest juice quality parameters, and nutrient uptake
}

\author{
Jonathan Martin
}

Vineyard management practices have an impact on grape berry development in ways that influence the quality of wine made from those grapes. The goal of this study is to determine whether exogenous applications of marine extracts on Syrah grapes can influence yield components, harvest juice quality parameters, and nutrient uptake. From 2009 to 2011, Syrah grape vines at the Trestle Vineyard on the California Polytechnic State University, San Luis Obispo campus received individual doses of marine extract via fertigation at berry set and veraison proportional to the amount they would receive on an annual per-acre basis. In 2011, marine extracts were also applied as foliar treatments. Treatments were analyzed for the effects on TSS, pH, TA, anthocyanins, tannins, fruit yield per vine, clusters per vine, average berry weight, cluster weight, berries per cluster, vegetative yield, and nutrient uptake. The marine extracts did not have any significant effects on yield components, harvest juice quality, or nutrient uptake at any point in this experiment. Therefore, there appears to be no benefit to applying these products in Syrah grapes growing in heavy clay soil in cool-climate conditions. 


\section{TABLE OF CONTENTS}

\section{Page}

List of Figures $\ldots \ldots \ldots \ldots \ldots \ldots \ldots \ldots \ldots \ldots \ldots \ldots \ldots \ldots \ldots \ldots \ldots \ldots \ldots \ldots \ldots \ldots \ldots \ldots$

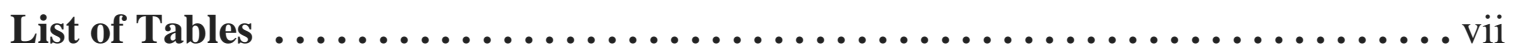

Chapter 1: Literature Review $\ldots \ldots \ldots \ldots \ldots \ldots \ldots \ldots \ldots \ldots \ldots \ldots \ldots \ldots$

1.1. Quality Parameters $\ldots \ldots \ldots \ldots \ldots \ldots \ldots \ldots \ldots \ldots \ldots \ldots \ldots \ldots \ldots \ldots$

1.2. Plant Hormones in Grapevines $\ldots \ldots \ldots \ldots \ldots \ldots \ldots \ldots \ldots \ldots \ldots$

1.3. Grapevine Nutrition $\ldots \ldots \ldots \ldots \ldots \ldots \ldots \ldots \ldots \ldots \ldots \ldots \ldots \ldots$

1.4. Marine Resource Utilization in Agriculture ................. 20

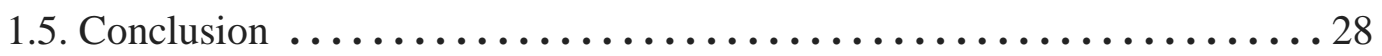

Chapter 3: Materials and Methods $\ldots \ldots \ldots \ldots \ldots \ldots \ldots \ldots \ldots \ldots \ldots \ldots \ldots \ldots$

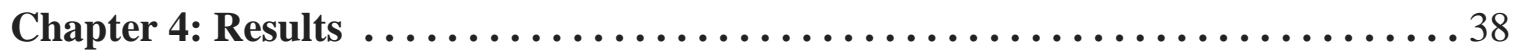

Chapter 5: Discussion and Conclusion $\ldots \ldots \ldots \ldots \ldots \ldots \ldots \ldots \ldots \ldots \ldots$

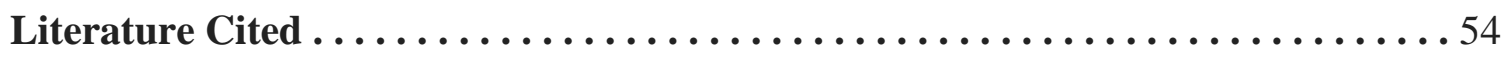

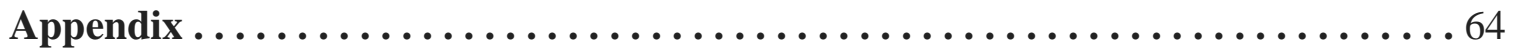




\section{LIST OF FIGURES}

Figure $\quad$ Page

Figure 1.1. Grape berry development from flowering until harvest. 29

Figure 1.2. Countries where agricultural use of seaweed has been documented. 30

Figure 2.1. Map of the fertigation experiment conducted using Syrah vines on 36

Schwarzmann rootstock at the Trestle Vineyard, California Polytechnic State University, San Luis Obispo, CA.

Figure 2.2. Map of the foliar fertilizer experiment conducted using Syrah vines on 420A rootstock at the Trestle Vineyard, California Polytechnic State University, San Luis Obispo, CA. 
Table 1.1. Common grapevine rootstocks parentage and characteristics.

Table 1.2. Total foliar $\mathrm{N}, \mathrm{P}, \mathrm{K}$ (\% dry weight) and $\mathrm{NH}_{4}{ }^{+}, \mathrm{NO}_{3}{ }^{-}, \mathrm{Zn}$, and $\mathrm{B}$ (ppm dry weight) of 12 wine grape cultivars.

Table 2.1. Total amount of macronutrients (kg/ha/yr) applied in 2009 and 2010 by soil fertigation to Syrah vines at the Trestle Vineyard, California Polytechnic State University, CA.

Table 3.1. Effect of fertigation treatment on harvest juice TSS $\left({ }^{\circ} \mathrm{Brix}\right), \mathrm{pH}$, TA (g/100ml), sugar-to-acid ratio (TSS: TA), anthocyanins (mg/L), tannins (mg/L), and anthocyanin:tannin ratio of Syrah grapes harvested on 21 September 2009 from Trestle Vineyard, California Polytechnic State University, San Luis Obispo, CA.

Table 3.2. Effect of fertigation treatment on clusters per vine, berries per cluster, cluster weight $(\mathrm{g})$, average berry weight $(\mathrm{g})$, fruit yield per vine $(\mathrm{kg})$, vegetative yield per vine, and Ravaz Index of Syrah grapes harvested on 21 September 2009 from Trestle Vineyard, California Polytechnic State University, San Luis Obispo, CA.

Table 3.3. Effect of fertigation treatment on fruit yield per vine $(\mathrm{kg})$, clusters per vine, berries per cluster, cluster weight (g), average berry weights (g), and rachis lengths $(\mathrm{mm})$ of fertigation-treated Syrah grapes harvested on 1 August 2011 from Trestle Vineyard, California Polytechnic State University, San Luis Obispo, CA.

Table 3.4. Effect of foliar treatment on fruit yield per vine $(\mathrm{kg})$, clusters per vine, berries per cluster, cluster weight (g), average berry weights $(\mathrm{g})$, and rachis lengths $(\mathrm{mm})$ of foliar-treated Syrah grapes harvested on 1 August 2011 from Trestle Vineyard, California Polytechnic State University, San Luis Obispo, CA.

Table 3.5. Effect of fertigation by treatment and year on fruit yield per vine $(\mathrm{kg})$, clusters per vine, berries per cluster, cluster weight (g), and average berry weights ( $\mathrm{g}$ ) of Syrah grapes harvested on 1 August 2011 from Trestle Vineyard, California Polytechnic State University, San Luis Obispo, CA.

Table 3.6. Petiole $\mathrm{NO}_{3}^{-}$(ppm dry weight), \% dry weight leaf blade $\mathrm{N}, \%$ dry weight petiole $\mathrm{P}, \mathrm{K}, \mathrm{Ca}$, and $\mathrm{Mg}$, and ppm dry weight petiole $\mathrm{Zn}, \mathrm{Mn}, \mathrm{Fe}, \mathrm{B}$, and $\mathrm{Cu}$ of petioles and leaves harvested from fertigation-treated Syrah vines on 1 August 2011 at Trestle Vineyard, California Polytechnic State University, CA.

Table 3.7. Petiole $\mathrm{NO}_{3}{ }^{-}$(ppm dry weight), $\%$ dry weight leaf blade $\mathrm{N}, \%$ dry weight petiole $\mathrm{P}, \mathrm{K}, \mathrm{Ca}$, and $\mathrm{Mg}$, and ppm dry weight petiole $\mathrm{Zn}, \mathrm{Mn}, \mathrm{Fe}, \mathrm{B}$, and $\mathrm{Cu}$ of petioles and leaves harvested from foliar-treated Syrah vines on 1 August 2011 at Trestle Vineyard, California Polytechnic State University, CA. 
Table 3.8. Net photosynthetic rate ( $\left.\mu \mathrm{mol} \mathrm{CO} \mathrm{Cm}^{-2} \mathrm{~s}^{-1}\right)$ and stomatal conductance (mol $\mathrm{H}_{2} \mathrm{O} \mathrm{m}^{-2} \mathrm{~S}^{-1}$ ) of Syrah grape leaves immediately after application of seaweed extract, fish/seaweed extract blend, or water (Control) on 17 August 2009 at Trestle Vineyard, California Polytechnic State University, San Luis Obispo, CA. 


\section{CHAPTER 1 \\ LITERATURE REVIEW}

\subsection{QUALITY PARAMETERS}

Grape berry development. Grape berries follow a double-sigmoid pattern of growth with three phases. Phase I follows flowering with the formation of berries. During phase I, berries grow increasingly larger due to cell division and elongation (Figure 1.1). Phase I ends with bunch closure, when the clusters become more compact. Berry growth slows substantially during phase II, it is therefore also referred to as "lag phase." During phase II, acidity peaks and then gradually declines as sugar development begins. At lag phase, berries are approximately half of their final harvest weight, though final harvest weights ranging from 1.7 to 2.6 times their lag phase weight have been observed [1]. Phase III starts at veraison, when the grape berries change color and soften. During phase III, grape berries increase in size due to cell elongation and start to accumulate color and flavor compounds $[2,3]$. Between veraison and harvest, titratable acidity (TA) declines while total soluble solids (TSS) and pH increase.

TSS, pH, and TA. The three main berry chemistry parameters used to evaluate harvest juice quality are TSS, pH, and TA. All sugars are considered TSS and are expressed as ${ }^{\circ}$ Brix. TSS accumulate most rapidly with daytime temperatures from 18 to $33^{\circ} \mathrm{C}$ and are delayed by cool and hot daytime temperatures, high winds, high crop load, fruit zone shading, soil moisture, high soil nitrogen (N) [4-9], and virus pressure [10-12]. The TSS content at harvest will determine the alcohol content of the finished wine. Most red wine grapes are picked at approximately $24{ }^{\circ}$ Brix, although wine grapes can be picked later if higher alcohol wines are desired. As TSS increase, the breakdown of malic acid during respiration results in decreased $\mathrm{TA}$ and increased $\mathrm{pH}$ [2]. Winemakers will typically 
harvest at approximately $24-26^{\circ}$ Brix in order to maintain high TA and low $\mathrm{pH}$. Wine with a $\mathrm{pH}$ above 3.6 and/or low TA will have a greater susceptibility to spoilage and less color stability than more acidic, lower $\mathrm{pH}$ wines [4]. Ideally, the TSS content preferred by the winemaker will coincide with low $\mathrm{pH}$, high $\mathrm{TA}$, high phenolics, and a strong flavor and aroma profile.

Phenolics. Phenolics are organic compounds metabolized by plants as a means of defending themselves against pests and environmental stress. All phenolics are either nonflavonoid or flavonoid, with anthocyanins, tannins, and flavonols classified as flavonoids. Anthocyanins are the pigments that give color to wine, while flavonols and tannins are responsible for bitterness and astringency, respectively [13]. Both tannins and flavonols bind to anthocyanins during the winemaking and aging process, resulting in color stability over time. Flavonoid synthesis is increased by exposure to light; however, red grapes will develop more anthocyanins with cool daytime temperatures. Flavonoid synthesis is hindered by high crop load, low-light conditions and high temperatures, with high night time temperatures causing flavonoid degradation [14].

Flavor and aroma compounds. Two groups of compounds that are strongly influenced by environmental conditions and management practices that have a strong impact on wine quality assessment are monoterpenes and methoxypyrazines. Free monoterpenes impart tropical fruit aromas and are encouraged by light in the fruit zone. Methoxypyrazines are responsible for green bell pepper and vegetal aromas, which are not considered favorable in red wines. Methoxypyrazines are degraded by exposure to light, while excess vigor causing shading in the fruit zone will aid in their formation [15]. Yield. In contrast to most fruit crops, high yields are usually not desired in premium wine grape production. 
High crop loads can delay TSS accumulation, possibly resulting in grapes not reaching their target ${ }^{\circ}$ Brix before the end of the growing season [4]. Since anthocyanins and flavonols accumulate in the skins, it is assumed that wine made from smaller grapes with a higher skin-to-pulp ratio will have better color, aging stability, and flavor potential than wine from larger, juicier berries [16]. Larger berries also pose the added danger of forming tighter, more compact clusters, increasing the risk of development of fungal diseases such as Botrytis cinerea [17]. However, researchers have found that wine quality parameters can remain unaffected by increasing yields and berry sizes [16], and in some cases improve with increasing yields up to a maximum yield specific to that vineyard [18]. Many of the desirable qualities of wine made from smaller berries are indirect effects of management practices common in premium wine grape vineyards, such as deficit irrigation and leaf pulling, which result in small, flavonoid-rich berries [13, 16, 19]. The fruit yield to vegetative yield ratio, known as the Ravaz Index, shows a stronger correlation to wine quality than fruit yields alone $[18,20]$. Therefore, any management strategy should be focused on maintaining the fruit yield to vegetative yield ratio that is best suited to the cultivar and growing conditions in order to maximize wine quality and economic returns.

Fruit yields can vary from year-to-year and vineyard to vineyard based on environmental conditions and management practices. High rainfall in the previous winter can increase the availability of soil moisture during early vegetative growth, leading to higher cluster weights at fruit set [18]. Frost events after budbreak or extreme temperatures and precipitation during bloom can cause substantial yield losses by reducing the number and size of fruit clusters [21-23]. Fruit yield can also be influenced 
by management practices such as irrigation strategy [13], canopy manipulation [24], pruning [24], fertilizers [25, 26], biostimulants [27-35], and rootstock selection [36]. Rootstock selection has a strong impact on yield components due to its role in regulating vigor and nutrient uptake (Table 1.1) [36]. Low vigor rootstocks, such as 420A and 3309C, will produce smaller clusters than medium and high vigor rootstocks [36]. Yields are also influenced by vine-yield compensation, the inverse relationship between cluster number and berry size and/or number. For example, when clusters numbers are reduced due to cluster thinning or pruning, cluster weights increase due to increased berry size and/or increased berries per cluster [24].

\subsection{PLANT HORMONES IN GRAPEVINES}

Introduction. Plant hormones are compounds produced and transported within plants that regulate growth and development. Changes in concentrations of auxins, cytokinins, gibberellins (GAs), and abscisic acid (ABA) control the timing of all growth stages in grapevines and can influence yield components, harvest juice quality parameters, and phenolics [37-39].

Auxins. Auxins are produced in grapevine shoot tips, leaves, and seeds. The primary roles of auxins are to promote cell elongation, cell division, nutrient transport, and lateral root formation [40], and to inhibit the ripening process until conditions are ideal for seed dispersal [37, 38]. Since zinc $(\mathrm{Zn})$ is required for auxin formation, the tiny berries commonly referred to as "shot" that are observed when grape berries are deficient in $\mathrm{Zn}$ could be attributed to a lack of cell elongation and division as a result of insufficient auxin levels [41]. In reproductive structures, auxins are at their highest concentration from 
flowering until the initiation of berry set, and decline in concentration throughout berry growth [42]. Synthetic auxin application delayed ripening by 10-14 days in Syrah grapes $[37,38]$ and suppressed sugar and anthocyanin accumulation in Cabernet Sauvignon [43]. This suggests that reductions in auxin concentration below a certain threshold or a low auxin to $\mathrm{ABA}$ ratio might be required in order to commence veraison [37, 38, 42].

GAs. GAs are synthesized early in the growing season in the roots, shoots and leaves and reach their maximum concentration in grape berries during phase I of berry growth [39]. Berry GAs decline in concentration to their lowest levels at the start of veraison. In grape berries, GAs primarily promote cell elongation, in addition to promoting cell division, seed germination, emergence from dormancy, and monoterpene biosynthesis [39, 44, 45]. Synthetic GAs are commonly used to enlarge seedless table grapes and loosen clusters [46]. GA application has been shown to increase berry weights in seedless grapes [27, 29, 47-49], with recorded increases in over 100\% [27]. However, results are less favorable with seeded wine grapes. GA decreased cluster weights and berries per cluster while increasing berry shatter and the percentage of shot berries in White Riesling and Pinot Blanc [50] and delayed TSS accumulation in Thompson Seedless and Ruby Seedless grapes [27, 47, 49, 51]. Therefore, the use of exogenous GA on grapes is limited to seedless table grapes and is not recommended for wine grapes.

Cytokinins. Cytokinins are formed in grapevine root tips and seed embryos. Cytokinin synthesis is increased by warm temperatures and sunlight, signaling budburst and berry set. Cytokinins initiate cell division in grape berries during phase I of berry growth, leading to berry enlargement [40]. While cytokinins encourage cell division in berries, leaves, and lateral shoots, cytokinins inhibit cell division in roots [40]. The synthetic cytokinin, 
forchlorfenuron (CPPU), can be used to increase grape berry size, resulting in compact clusters and berry weight increases of 52-100\% relative to the control [35]. However, CPPU application can decrease TSS by as much as $4^{\circ}$ Brix, and is therefore not widely used in table or wine grape production $[34,35,52]$.

ABA. ABA is produced in the roots and leaves of grapevines. During stressed conditions, ABA signals the closure of stomata in order to conserve water [43]. This effect has been observed with exogenous $\mathrm{ABA}$ applications to crops such as bentgrass, resulting in temporary reductions in net photosynthesis, stomatal conductance, and transpiration [53]. While auxins, cytokinins, and gibberellins decline in concentration towards veraison, berry ABA concentration is highest in the first few weeks of phase III [28]. The start of phase III begins when the auxin to ABA balance reaches a certain minimum threshold [39]. This results in an increase in anthocyanin production, causing rapid coloration of berries [43, 54].

The ability of exogenous $\mathrm{ABA}$ applications to rapidly increase grape color at the start of veraison is well demonstrated and might result in higher anthocyanins at harvest in some cultivars [28, 30-33, 55]. Synthetic ABA was approved for agricultural use in the state of California under the brand names "Contego" and "Protone" in 2010 [56]. Exogenous ABA applications have been shown to increase anthocyanins and flavonols in table and wine grapes $[28,30-33,55]$. Recently, ABA was shown to stimulate anthocyanin synthesis in grape cell cultures [54] and has been shown to increase the concentration of the regulatory gene and enzyme genes that control the anthocyanin biosynthetic pathway [43]. Exogenous ABA applied to Flame Seedless table grapes at veraison increased anthocyanin content by as much as $800 \%$ compared to the untreated control [32]. 
Exogenous ABA applied directly to Merlot clusters resulted in a $7 \%$ increase in anthocyanins as compared to those of untreated vines [55]. Exogenous ABA applications also resulted in increased anthocyanins in greenhouse-grown Pinot noir [31]. Exogenous ABA applications increased Cabernet Sauvignon berry flavonol concentration throughout ripening and resulted in significantly greater berry anthocyanin content at the start of veraison compared to non-treated grapes. However, at $80 \%$ red coloration, control and ABA treated berries were almost equal in anthocyanin content, with no significant differences in anthocyanin content at harvest. This suggests that exogenous ABA might not be able to increase anthocyanins at harvest in Cabernet Sauvignon [28]. Exogenous ABA applications did not affect TSS, pH, TA, fruit yield or berry weight in any of these studies $[28,30-33,55]$.

\subsection{GRAPEVINE NUTRITION}

Introduction. Grapevines require the same 16 elements for growth as all other higher plants. The requirement for carbon, hydrogen and oxygen are satisfied by rainfall, irrigation water, and the atmosphere. The remaining nutrients must be absorbed from the soil by grapevine roots and/or applied directly to the grapevines in order to sustain growth and proper fruit development. When abundant, many elements will decrease or increase the availability of other elements, leading to nutrient deficiencies or excesses, which could have negative side effects on grapevine growth and wine quality [57-59].

N. $\mathrm{N}$ deficiency affects more acreage than any other nutritional element in California vineyards [58]. Grapevines require $\mathrm{N}$ for amino acid, lecithin, and chlorophyll synthesis, 
making $\mathrm{N}$ crucial for growth and development. Soil microbes convert ammonium $\left(\mathrm{NH}_{4}{ }^{+}\right)$ and other $\mathrm{N}$ compounds into nitrate $\left(\mathrm{NO}_{3}^{-}\right)$, a highly soluble form of $\mathrm{N}$ that moves through the soil via mass flow $[57,59]$. $\mathrm{N}$ stored in roots is mobilized immediately after budbreak, with a sharp increase in soil $\mathrm{N}$ uptake by the roots during the first root flush that starts at bloom and continues until veraison [60]. No additional $\mathrm{N}$ uptake occurs between veraison and harvest [60]. At harvest time, approximately one-third to one-half of the vines' total $\mathrm{N}$ is stored in the fruit and subsequently removed from the vineyard [60]. Approximately onethird of the vine's total $\mathrm{N}$ at harvest is stored in the current season's leaves and shoots, while the remainder is retained by the trunk, canes, and roots [60]. $\mathrm{N}$ uptake resumes at harvest and halts at the end of leaf abscission during the second root flush, during which the majority of the remaining $\mathrm{N}$ is translocated into the roots and trunk [60]. Grapevines absorb a substantial portion of their annual $\mathrm{N}$ requirement post-harvest, resulting in $\mathrm{N}$ reserves that support the following season's growth [60].

Of the 13 plant essential nutrients found in soil, $\mathrm{N}$ is the only element that is not weathered from minerals [58]. Sources of $\mathrm{N}$ include decomposing organic matter, biologically-fixed $\mathrm{N}$ from leguminous ground cover, and dissolved $\mathrm{NO}_{3}{ }^{-}$in irrigation or rainwater, which might provide enough $\mathrm{N}$ so that supplemental $\mathrm{N}$ fertilization is unnecessary in some vineyards $[58,61]$. To determine if applications of $\mathrm{N}$ are required, $\mathrm{N}$ status of grapevines is typically determined by taking petiole samples at full bloom. $\mathrm{N}$ deficiency symptoms often appear after the deficiency is established, and include reduced vigor, pale foliage, and reduced fruit yield. $\mathrm{N}$ excess accelerates vine vigor, causing the vine to form longer shoots and larger, darker green leaves [58]. Excess $\mathrm{N}$ can reduce fruit yield, TSS [5, 7-9, 62, 63], and anthocyanins [25], while increasing pH [5, 64-66]. 
Excessive $\mathrm{N}$ also leads to increased vigor and fruit zone shading, resulting in the formation of vegetal aromas [15, 67], while hindering the synthesis of anthocyanins and favorable fruity aromas that require filtered light [15]. The negative influence of excess $\mathrm{N}$ on yield and harvest juice quality parameters has resulted in relatively low fertilization recommendations (50-56 kg N/ha per year) as compared to other perennial fruit crops [58, $61]$.

$\mathrm{N}$ fertilization can alter vine uptake of nutrients. The effect of pre- and early season $\mathrm{N}$ fertilization on bloomtime petiole $\mathrm{N}$ is highly dependent on cultivar (Table 1.1) [62], rootstock [68, 69], irrigation [70], and canopy/crop manipulation [24]. Early season N fertilization resulted in increased bloom petiole $\mathrm{N}$ in all tested cultivars [6, 7, 26, 68]. Early season $\mathrm{N}$ fertilization resulted in decreased Phosphorus $(\mathrm{P})$ status in Cabernet Sauvignon [71], Riesling [8], Merlot [7] and Chenin Blanc [61]. Riesling bloomtime leaf Magnesium $(\mathrm{Mg})$ and calcium $(\mathrm{Ca})$ increased with $\mathrm{N}$ fertilization rate during the spring [8], whereas Merlot petiole $\mathrm{Mg}$ and Ca were negatively correlated with $\mathrm{N}$ [7]. Increasing $\mathrm{N}$ fertilization in the spring resulted in increased bloomtime petiole sulfur (S) in Merlot [7] and decreased petiole $S$ in Chenin Blanc [5].

Increasing $\mathrm{N}$ fertilization is strongly correlated with increased vegetative yields in grapevines, and can have stronger effects when applied during root flushes. Increases in vegetative yields and leaf area as a result of $\mathrm{N}$ application have been observed in many cultivars, including Riesling [26], Chenin blanc [61], Cabernet Sauvignon [71], and Merlot [7]. Cabernet Sauvignon shoot growth, leaf growth, and number of leaves per vine at harvest was positively correlated with $\mathrm{N}$ fertilization rates during bloom [25]. Increases in Merlot canopy density were observed when $40 \mathrm{~kg} \mathrm{~N} / \mathrm{ha}$ was and post-harvest, as compared 
to applying 40 or $80 \mathrm{~kg} \mathrm{~N} / \mathrm{ha}$ at budbreak or bloom, respectively [63]. Fifty g N/vine, split between two applications at late budburst and two weeks after bloom, resulted in increased Cabernet Sauvignon vegetative yield, shoot length, vine density, leaf number, and the proportion of interior leaves as compared to the control. However, Neilsen (2010) found that the vegetative yields and shoot lengths of vines treated with $400 \mathrm{~g} \mathrm{~N} /$ vine were not significantly different from unfertilized control vines [71]. This suggests that increasing rates of $\mathrm{N}$ fertilization will rapidly increase vegetative yield in grapevines up to a certain point, after which vegetative yields plateau or possibly decline due to $\mathrm{N}$ toxicity [71].

Effects of $\mathrm{N}$ fertilization on fruit yield components are dependent on prefertilization $\mathrm{N}$ content and cultivar. Increasing $\mathrm{N}$ fertilization rates can substantially improve fruit yield components if there is a pre-existing $\mathrm{N}$ deficiency $[25,26]$. Conversely, Thompson Seedless grapevines fertilized with $0,112,224$, or $448 \mathrm{~kg} / \mathrm{ha} \mathrm{N}$ showed no significant differences in fruit yield per vine, total clusters, or cluster weight [64]. Bell et al. (1978) found that $112 \mathrm{~kg} \mathrm{~N} / \mathrm{ha}$ resulted in $12-16 \%$ higher fruit yields as compared to the unfertilized control [72]. Merlot vines treated with 40 or $80 \mathrm{~kg} \mathrm{~N} / \mathrm{ha}$ at budbreak had lower yields than vines receiving the same application rates at bloom, while the same $\mathrm{N}$ treatments had minimal effects on Cabernet Sauvignon vines in the same experiment [7, 63]. In that same study, applications of $80 \mathrm{~kg} \mathrm{~N} / \mathrm{ha}$ resulted in reduced Merlot fruit yield as compared to $40 \mathrm{~kg} \mathrm{~N} / \mathrm{ha}$ when applied at the same phonological stage [63]. Applications of $100 \mathrm{~g}$ N/vine split between budbreak and bloom resulted in an increased Ravaz Index of Cabernet Sauvignon by 56\% compared to the control. No further increases in fruit yield were detected with applications of $200 \mathrm{~g} \mathrm{~N} / \mathrm{vine}$ and $400 \mathrm{~g} \mathrm{~N} /$ vine resulted in decreased fruit yield as compared to all other treatments in 2 of the 3 study years [71], indicating that 
excess $\mathrm{N}$ could decrease fruit yields. Fruit yield reductions from increased $\mathrm{N}$ fertilization rates have also been observed in Chardonnay [66] and Syrah [68].

The accumulation of TSS are often delayed by excessive $\mathrm{N}$ application. Hilbert found that Merlot juice from a "limited" N application treatment had 2.4 and 2.8 greater ${ }^{\circ}$ Brix than the "mean" $\mathrm{N}$ treatment (2.5 times more applied $\mathrm{N}$ than the "limited" rate) and "excessive" $\mathrm{N}$ treatment (5 times more applied $\mathrm{N}$ than the "limited" rate), respectively [7]. In a 3 year study, Spayd (1994) determined that fertilizing White Riesling grapes with 56 kg N/ha/year applied in split applications between budbreak and fruit set delayed the accumulation of $21^{\circ}$ Brix by an average of six days relative to the control, while applications of $224 \mathrm{~kg} \mathrm{~N} / \mathrm{ha} / \mathrm{year}$ delayed harvest by an average of 16 days and as much as 22 days in one year [5]. TSS reductions as a result of $\mathrm{N}$ fertilization have also been observed in Niagara, Concord [9], Grenache, Barbera, Chenin blanc, and French Colombard [6]. However, no significant $\mathrm{N}$ treatment effects on TSS were observed in similar studies of Chenin blanc [61], Cabernet Sauvignon [63] or Thompson Seedless [64].

$\mathrm{N}$ fertilization can have variable effects on $\mathrm{pH}$ and titratable acidity (TA). The timing of $\mathrm{N}$ fertilization of Reisling vines had no effect on must $\mathrm{pH}$ at application rates of up to $90 \mathrm{~kg} \mathrm{~N} / \mathrm{ha}$ per year, and negligible effects on TA in Riesling [8], Cabernet Sauvignon, and Merlot [63]. Hilbert (2003) found that an "excessive" N application rate of Merlot resulted in the highest TA, while $\mathrm{pH}$ was unaffected as compared to the "mean" and "limited" N application rates [7]. Similar results were observed in a study of Grenache and Chenin Blanc, in which $112 \mathrm{~kg} \mathrm{~N} / \mathrm{ha}$ resulted in increased TA in one year of a four year study, with no significant effect on $\mathrm{pH}$ [6]. However, in White Riesling grapes, increased $\mathrm{N}$ fertilizer rates ranging from 56 to $224 \mathrm{~kg} \mathrm{~N} / \mathrm{ha} / \mathrm{year}$ were positively correlated 
with $\mathrm{pH}$ without having a significant effect on TA [5]. Both $\mathrm{pH}$ and TA increased as a result of 30 or $60 \mathrm{~kg} \mathrm{~N} / \mathrm{ha}$ applied at bloom in Riesling [65], with the higher TA attributed to increased malate production.

While some $\mathrm{N}$ is required for phenolic synthesis, $\mathrm{N}$ excess can reduce wine quality by decreasing phenolics and encouraging the formation of less-desirable flavor compounds. Fermentation rate is positively correlated with must $\mathrm{N}$ content; therefore, insufficient $\mathrm{N}$ can lead to slower and incomplete fermentations [12], which could then hinder phenolic synthesis [64]. Unfertilized Thompson Seedless vines produced wine with lower aroma, flavor, and wine quality than vines receiving $112 \mathrm{~kg} \mathrm{~N} / \mathrm{ha} / \mathrm{year}$, presumably due to a reduction in wine volatile formation caused by a slow fermentation rate [64]. Conversely, Cabernet Sauvignon berries from vines treated with $0.34 \mathrm{~g} \mathrm{~N} / v i n e$ applied at bloom had greater anthocyanins at veraison than berries from vines treated with 1.7 or 3.4 $\mathrm{g}$ N/vine [25]. Hilbert determined that Merlot berries from the "limited" $\mathrm{N}$ treatment had significantly higher berry skin anthocyanin content as compared to the "mean" and "excessive" N treatments [7]. Cabernet Franc wine from vines treated with $20 \mathrm{t}$ cow manure/ha/year for 28 years had significantly higher herbaceous/vegetative and animal odors, in addition to significantly lower color intensity, anthocyanins, tannins, aroma intensity, and astringency than control wines [67].

P. $\mathrm{P}$ is a primary macronutrient that is immobile in the soil and moves through the soil by diffusion $[57,58]$. Most soil $\mathrm{P}$ is derived from the breakdown of $\mathrm{Ca}$, iron $(\mathrm{Fe})$, and aluminum phosphates [59]. $\mathrm{P}$ uptake typically occurs in the orthophosphate $\left(\mathrm{H}_{2}-\mathrm{PO}_{4}^{-}\right)$form, which is highly mobile in the vine. P stored in the root tissue is used for early season growth at the start of budbreak. Root uptake of $\mathrm{P}$ increases as the season progresses towards 
veraison. Between veraison and harvest, root uptake of $\mathrm{P}$ stops, while $\mathrm{P}$ is translocated from the leaves into the clusters. Between harvest and leaf abscision, roots resume uptake of $\mathrm{P}$, which is then stored during dormancy and used for the next season's growth [73].

$\mathrm{P}$ is required for energy transfer within the vine and is crucial for reproductive growth $[74,75]$. P deficiency causes basal leaves to turn yellow and abscise prematurely, and appears as an interveinal reddening pattern starting from the edge of the leaves. $\mathrm{P}$ deficiency leads to severe yield losses by reducing canopy growth, berries per cluster, clusters per vine, cluster weights, and the number of initiated cluster primordia $[74,75]$. Despite its importance, $\mathrm{P}$ deficiency in vineyards is extremely rare and has only been observed in a few isolated areas with poor, low $\mathrm{pH}$ soils and low cation exchange capacity [76]. P status is most accurately assessed by leaf analyses at bloom [74]. Since P fertilization is rarely needed, $\mathrm{P}$ excess is generally not a concern in California vineyards, although it could lead to Zn deficiency [59].

Potassium. Potassium $(\mathrm{K})$ is a macronutrient that is commonly deficient in vineyards, especially those with sandy soils [58]. Vines grafted to rootstocks with Vitis berlandieri parentage such as $420 \mathrm{~A}$ and $110 \mathrm{R}$ can have lower petiole $\mathrm{K}$ concentrations at bloom than vines with other rootstocks [77]. Soil K originates from the weathering of minerals such as micas and feldspars [59]. K moves through the soil by diffusion in less mobile forms and by mass flow when it becomes more soluble [57]. Root K uptake peaks between bloom and veraison. Grape clusters accumulate $\mathrm{K}$ between veraison and harvest as root $\mathrm{K}$ uptake decreases. K mobilization increases between harvest and leaf abscision, although there is no additional root $\mathrm{K}$ uptake in the post-harvest period [60]. 
$\mathrm{K}$ contributes to vine growth by facilitating cell division and aiding in the synthesis of carbohydrates and proteins. $\mathrm{K}$ is also important for frost protection, water relations and enzyme activity. K deficiency appears as a gradual yellowing of the leaves that is followed by leaf burn/curl and premature leaf abscision. Severe K deficiency could lead to reduced shoot growth that in combination with premature leaf abscision, causes severe yield reductions and delayed, uneven ripening [58]. $\mathrm{K}$ is typically applied to vineyards as $\mathrm{K}$ sulfate $\left(\mathrm{K}_{2}{ }^{-} \mathrm{SO}_{4}\right.$, commonly known as 'potash') due to its low cost, ease of application via drip irrigation, low salt content, and rapid uptake. $\mathrm{K}$ status is most accurately predicted with petiole samples taken at bloom, with less than $1 \%$ dry weight $\mathrm{K}$ considered deficient [58].

$\mathrm{K}$ fertilization can alter the status of other nutrients in petioles and in the juice from the berries. Conradie (1989) found that 45 or $90 \mathrm{~kg} \mathrm{~K} / \mathrm{ha}$ applied at post-harvest and budbreak to Chenin blanc resulted in increased foliar $\mathrm{K}$ and reduced petiole $\mathrm{Ca}$ and $\mathrm{Mg}$ concentrations, as compared to the control. Reductions in petiole $\mathrm{Ca}$ and $\mathrm{Mg}$ concentrations have also been observed in Concord vines with the application of $450 \mathrm{~kg} \mathrm{~K} / \mathrm{ha}$ at budbreak [42]. Previous research has also demonstrated that increasing rates of $\mathrm{K}$ fertilization can lead to increased berry $\mathrm{K}[61,78]$, which is associated with increased juice $\mathrm{pH}[61,78]$. Dundon and Smart (1984) determined that $1.62 \mathrm{~kg} \mathrm{~K} /$ vine applied 3 weeks after budbreak in a hot-climate vineyard only increased petiole $\mathrm{K}$ in one of the four years studied, and did not cause a corresponding increase in must $\mathrm{K}$ [79]. In that same study, $\mathrm{K}$ application in a cool-climate vineyard did not significantly increase petiole $\mathrm{K}$ concentrations in any of the 3 study years, despite soil exchangeable K concentrations as high as $1400 \%$ greater than the control [79]. While high harvest juice $\mathrm{pH}$ is often attributed to excess $\mathrm{K}$ fertilization, 
the excessive $\mathrm{K}$ fertilization in this experiment did not influence Syrah harvest juice $\mathrm{pH}$ or TA as compared to the control [79].

Ca. $\mathrm{Ca}$ is weathered from limestone and $\mathrm{FeCO}_{3}$ in the soil, and is the fifth-most common element in the earth's crust [57]. While Ca contents of different soils can vary widely, deficiency in vineyards is rarely observed due to their low $\mathrm{Ca}$ requirement [58]. $\mathrm{Ca}$ is applied to soils to improve water penetration and raise soil $\mathrm{pH}$. The majority of $\mathrm{Ca}$ uptake occurs between bloom and veraison. Ca is relatively immobile in the vine and is stored in large quantities by vine bark [73]. Ca deficiency inhibits root and shoot growth, while excess Ca can reduce $\mathrm{K}$ and $\mathrm{Mg}$ uptake [57].

Mg. Mg is weathered from Mg-rich minerals such as Serpentine, Magnesite, Sulfite, Dolomite, and Olivine [57]. Mg is a component of chlorophyll molecules, making it indispensable for photosynthesis and vine growth [57]. Mg uptake in grapevines is unique compared to the macronutrients $\mathrm{N}, \mathrm{P}, \mathrm{K}$, and $\mathrm{Ca}$, in that grapevine roots absorb $\mathrm{Mg}$ continuously from early season growth until the start of leaf abscission [73]. Mg deficiency begins as leaf chlorosis at the margins that spreads into the areas between the smaller veins while the leaf tissue around the large veins remains green [58]. Mg deficiency can reduce yield and delay ripening if leaf chlorosis becomes severe enough to inhibit photosynthesis [58]. $\mathrm{Mg}$ deficiency is not common in California and is often isolated to a few vines or small areas in a vineyard [58]. While excess $\mathrm{Mg}$ can lead to $\mathrm{K}$ deficiency, the lack of $\mathrm{Mg}$ deficiency means that $\mathrm{Mg}$ fertilization is generally not required [58].

S. $\mathrm{S}$ is a constituent of proteins and enzymes [80]. $\mathrm{S}$ is present in soils as sulfates in soil solution, minerals, and organic matter [57]. Approximately 14 million kg S/year are applied to California vineyards as a foliar spray for powdery mildew control [81]. S deficiency 
causes a uniform leaf chlorosis that slows vine growth, however it is rarely seen in vineyards [73]. Soil acidification can result from excess $\mathrm{S}$ levels in the soil [82].

Zn. $\mathrm{Zn}$ is the second-most common nutrient deficiency in California vineyards. All soils are very low in $\mathrm{Zn}$ content and over $90 \%$ of soil $\mathrm{Zn}$ is bound in mineral form [57]. $\mathrm{Zn}$ is required for the synthesis of auxins, chlorophyll, and starch. Grapevines require approximately $0.5 \mathrm{~kg} \mathrm{Zn/ha/year} \mathrm{for} \mathrm{sufficient} \mathrm{internode} \mathrm{elongation,} \mathrm{leaf} \mathrm{growth,} \mathrm{pollen}$ development, pollen tube growth, berry count, and berry enlargement, making $\mathrm{Zn}$ essential for fully developed clusters $[58,83]$. Reduced leaf expansion, chlorotic leaf blades with dark green veins, stunted shoots, and withered clusters with tiny, under-ripe berries are all characteristics of $\mathrm{Zn}$ deficiency. The underdeveloped clusters and the reduced photosynthetic capacity of the shoot system can lead to substantial yield losses and delayed ripening in grapes. Soil $\mathrm{Zn}$ status is not a reliable indicator of vine $\mathrm{Zn}$ status, and tissue analysis is often not necessary due to the obvious fruit and canopy symptoms. If tissue analysis is used, Zn petiole dry weights lower than $13 \mathrm{ppm}$ are deficient [83]. Soil Zn applications are usually unsuccessful due to rapid $\mathrm{Zn}$ fixation by most soils. Foliar application of $\mathrm{ZnSO}_{4}$ between bud break and bloom or daubing fresh pruning cuts with $\mathrm{ZnSO}_{4}$ are the only practical ways to correct $\mathrm{Zn}$ deficiency in most vineyards $[58,83]$. Excess Zn can restrict root growth and induce chlorosis in young leaves [59].

Boron. Boron (B) is one of the micronutrients of greatest difficulty to correct due to the extremely narrow range between soil B deficiency and toxicity. B is more abundant in soils with sedimentary parent material rich in borosilicate minerals and in areas with B-rich irrigation water [58]. Vines absorb B as borate, which is used for new cell differentiation, carbohydrate metabolism, and pollen germination. Once in the vine, B is relatively 
immobile and is not translocated from older to younger leaves [58]. The role of B in pollen germination makes sufficient B a requirement for fruit set and yield. Severely reduced internode and shoot length, shoot tip death, low to non-existent fruit set, and tiny berries are all common symptoms of B deficiency. B is deficient for grape production if concentrations are below 0.15 or $0.1 \mathrm{ppm} B$ in soil extracts or irrigation water, respectively. However, B is toxic to grapevines with B concentrations greater than $1 \mathrm{ppm}$ in soil extracts or irrigation water [83]. B excess can reduce yields by causing cupped downward growth of leaves and leaf necrosis. Foliar application can temporarily correct B deficiency, although the results are typically short-lived [58]. B accumulates in leaf blades more so than petioles, therefore leaf blades are the best indicator of B status, with $30-80$ to ppm B petiole dry weight being the ideal range [84].

Fe. Fe is the third-most common micronutrient deficiency in California vineyards after $\mathrm{Zn}$ and B and is considered the most difficult nutrient deficiency to overcome [58]. Fe is found in a variety of minerals and composes $5.1 \%$ of the lithosphere. While Fe is the most common nutrient in soils, 90 to $99.98 \%$ of soil $\mathrm{Fe}$ is unavailable to plants [57]. Fe is needed for chlorophyll production, enzyme activation, and as a building block for organic compounds [58]. Fe's mobility is hindered in heavy soils or soils with high lime and phosphate, giving Fe deficiency leaf symptoms the name "lime-induced chlorosis." Fe is not mobile within the vine, therefore, it is not transported from older to younger leaves. Deficiency appears as a pale interveinal yellowing of the younger leaves, leading to reductions in shoot growth and yield. Fe toxicity can also reduce yield; however, $\mathrm{Fe}$ toxicity does not typically occur in vineyards. The high Fe fixing capacity of most soils means that the results of soil Fe fertilization are temporary, costly and impractical. Fe 
deficiency is best diagnosed with visual criteria, due to inconsistencies between soil $\mathrm{Fe}$, tissue Fe, and Fe deficiency symptoms. Fe deficiency can be corrected with foliar sprays of Fe chelates or Fe sulfates in 10-20 day intervals until symptoms disappear [58].

Manganese. Manganese (Mn) is weathered from ferromagnesian rocks in the soil and is used by vines for enzyme activation and chlorophyll formation [57]. Mn uptake occurs in the $\mathrm{Mn}$ ion form $\left(\mathrm{Mn}^{++}\right)$, after which it becomes immobile within the vine [58]. $\mathrm{Mn}$ deficiency is occasionally observed in vineyards and is most common in sandy, basic soils. Mn deficiency appears in mid-to-late summer as an interveinal chlorosis of the basal leaves. Since Mn deficiency only affects the less photosynthetically-active older leaves, yield losses from Mn deficiency are rarely a concern. Mn deficiency can be confirmed with petiole analysis, with deficiencies occurring below 20 to $25 \mathrm{ppm} \mathrm{Mn.} \mathrm{Mn} \mathrm{deficiency} \mathrm{can}$ be corrected by foliar application of $\mathrm{MnSO}_{4}$, although excess $\mathrm{Mn}$ application can cause leaf burn and deficiencies in other nutrients [58].

Copper. Copper $(\mathrm{Cu})$ is a micronutrient that is required by grapevines in trace amounts as a constituent of oxidation enzymes. $\mathrm{Cu}$ deficiencies have never been reported in California vineyards [58] and are considered to be rare worldwide [80]. However, they have been detected in a few vineyards in West Australia [80]. Cu deficiency can severely reduce productivity by reducing shoot length, internode length, leaf size, and leaf chlorophyll content. $\mathrm{Cu}$ toxicity can reduce vigor in the canopy and the root system, along with causing root system damage [80]. $\mathrm{Cu}$ is a common ingredient in fungicides applied in vineyards, the use of which could result in $\mathrm{Cu}$ toxicity in acidic soils, given that $\mathrm{Cu}$ availability is negatively correlated with soil $\mathrm{pH}[80,85]$. 
Molybdenum. Molybdenum (Mo) is a micronutrient that facilitates N metabolism [80]. Mo exists in very low quantities in the soil, and only a small handful of minerals are known to contain and weather Mo [57]. Plants require Mo in lower quantities than all other plant essential nutrients [57], and its deficiency has never been recorded in California vineyards [58]. Mo deficiency causes leaf chlorosis and necrosis, while toxicity leads to leaf malformation [59].

Chlorine. Chlorine $(\mathrm{Cl})$ is involved in photosynthesis and stomatal regulation, and is provided to grapevines as chloride $\left(\mathrm{Cl}^{-}\right)$in rain and irrigation water [57]. Due to its abundance in the environment, $\mathrm{Cl}$ deficiency has never been reported in vineyards [57, 58]. Leaf uptake of $\mathrm{Cl}^{-}$progresses with the growing season, and might be toxic in concentrations as low as $0.5 \%$ of leaf blade dry weight. $\mathrm{Cl}^{-}$toxicity first appears as leaf burn and can ultimately lead to reduction in vine growth and possibly death. $\mathrm{Cl}^{-}$toxicity in irrigation water is a major concern for grape growers in areas with highly saline irrigation water and/or poor soil drainage characteristics [58].

Conclusion. All plant essential nutrients contribute to vine growth and development. However, unless correcting nutrient deficiencies, fertilizers generally do not improve harvest juice quality parameters or yield components in ways that can potentially increase wine quality. Increased vigor actually decreases wine quality, TSS and phenolics. Nutrient management in vineyards requires regular assessment of leaf, petiole and/or soil nutrient content and the application of fertilizers accordingly. 


\subsection{MARINE RESOURCE UTILIZATION IN AGRICULTURE}

Origins of Fish-based Fertilizer in Agriculture. Nutrients suspended in aquatic environments are absorbed by fish throughout their life cycle [86]. Fish have, therefore, been used as fertilizer since the medieval period in France [87]. This use was first documented in an English publication from 1620. This tradition developed independently in Peru, where Incans used fish heads and guano as fertilizer [87]. At the present time, the non-edible remains and non-target species from the seafood processing and commercial fishing industries are converted into a variety of emulsions, extracts, powders, animal feeds, and potting soil amendments. Fish emulsion is made by boiling fish remains into a semi-soluble liquid fertilizer. Fish extracts are made by grinding fish remains and transferring them to a refrigerated holding tank for enzymatic hydrolysis, during which, the fish enzymes break down the remains into a liquid containing simpler proteins [88]. The extracts are then passed through a series of filter screens to remove bone particles [88]. Fish extracts are generally preferred to emulsions, due to the greater water-solubility and lesser smell of extracts. Most fish-based fertilizers contain between $2-4 \% \mathrm{~N}$ and $2-4 \% \mathrm{P}$ by volume [88]. In a survey of 300 certified organic vegetable farmers, fish-based products were used by $20 \%$ of the respondents, and were ranked the fourth-most commonly used nutrient source after manure, compost, and leguminous cover crops [89]. Despite their relatively low nutrient value when compared to synthetic fertilizers, fish-based fertilizers play an important role in reducing the waste disposal demands of the seafood industry, while simultaneously providing a nutrient source for organic growers. 
Effects of Fish-Based Fertilizer on Crop Yield. The nutrients found in fish have similar effects on yield as synthetic fertilizer when equal amounts of nutrients are applied. Radish, cucumber, potato, and tomato plants growing in a soil mix containing 1,2 , or $4 \%$ fish emulsion had yields that were not significantly different than those receiving synthetic fertilizer when equal amounts of $N$ were applied [90, 91]. Similar yield responses were observed in millet and groundnut plantations in Ghana, where treatments of 2000, 4000, and $6000 \mathrm{~kg}$ fish remains/ha resulted in the same yield increases as synthetic fertilizers treatments when equal amounts of $\mathrm{N}$ were applied [92]. Yields of fish emulsion-fertilized tomatoes, chili peppers, and ornamental plants had yields that were not significantly different from yields of crops receiving synthetic fertilizers with the same amount of applied N [93].

Fish-based fertilizers also have the potential to increase marketable yields through disease suppression. Radishes and cucumbers planted into soil incorporated with fish emulsion had reduced Rhizoctonia and Pythium symptoms, resulting in increased marketable yields as compared to synthetic $\mathrm{N}$ treatments. Verticilium rot and scab symptoms were also reduced on potato plants fertilizer with fish emulsion, resulting in increased marketable yields as compared to those treated with synthetic fertilizers [91]. However, no improvements in disease suppression, fruit size, or number of fruits were observed with soil treatments of fish emulsion in organic fresh market tomato production [94].

Most fish-based fertilizers contain relatively small quantities of N, P, and K, and even smaller concentrations of other macro- and micronutrients, as compared to commonly used synthetic fertilizers. For example, $\mathrm{N}$ in the forms of $\mathrm{NH}_{4} \mathrm{NO}_{3}(33-0-0)$ and urea (45- 
$0-0$ ) are 33 and $45 \% \mathrm{~N}$ by volume respectively [95], whereas a typical fish extract such as Neptune's Harvest (2-3-1) is only 2.4\% N [88]. When used at manufacturer-recommended rates, the effectiveness of fish-based fertilizers to increase yields is limited due to the low amount of nutrients applied. For example, Brown (2004) found that foliar applications of Neptune's Harvest Fish Extract 2-4-1 or Fish/Seaweed Blend extract 2-3-1 applied at the manufacturer's recommended rate of $112 \mathrm{~L} / \mathrm{ha}$ [88] did not result in significant changes in sweet pepper, broccoli, or lettuce yields [96]. Fish-based fertilizers also failed to increase yield or quality in tomatoes [94, 97], and wheat [98]. Yields of greenhouse-grown tomatoes were not significantly different when fertilized with fish emulsion or Hoagland's solution containing equal amounts of applied N. However the fish-emulsion treatment resulted in delayed ripening as compared to the Hoagland's treatment [99]. The low nutrient content per unit of cost and volume and general lack of yield increases or quality commodity improvement in response to fish-based fertilizers explains why their use is rare in conventional agriculture.

Origins of Seaweed-based Amendments in Agriculture. The use of seaweed for agricultural purposes is documented in 21 countries worldwide (Figure 1.2). At least 25 species of seaweed are used for fertilizer or animal feed across a wide variety of climates and cropping systems [100]. Along the Galician coast in northwest Spain, farmers have traditionally harvested drift seaweed and applied it to potatoes, grapevines, horticultural crops, and cereals [101]. Seaweed is especially useful in soils with low organic matter due to its ability to increase soil pore volume, aggregate stability, microbial biomass, and biological activity when incorporated into soil [102]. The use of seaweed extracts (SWEs) or concentrates is more common than using raw seaweed, due to its commercial availability 
and ease of application [103]. SWEs are prepared by harvesting raw seaweed in intertidal zones and breaking them down by enzymatic hydrolysis [88]. This process raises the concentration of organic compounds and plant growth regulators (PGRs) that are credited for the various crop responses to SWE. Exact formulas for SWE preparation vary by producer, as each manufacturer has their own proprietary formula and seaweed source that might increase or decrease its efficacy relative to their competitors $(\mathrm{H}$. Little, Acadian Seaplants, personal communication, February 28, 2011). Numerous PGRs have been found in seaweed and SWE, including cytokinins [104, 105], auxins [106, 107], GAs [108, 109], ABA [110], and betaines $[111,112]$. It is hypothesized that seaweed synthesizes relatively high concentrations of PGRs because this confers an adaptive advantage that allows it to survive the extreme temperature ranges and levels of desiccation characteristic of intertidal zones [113]. Other organic compounds that are yet to be identified might also be responsible for the effects of SWEs on crop growth and yield [107, 114]. The amount of plant essential nutrients in seaweed and SWEs is too low to meet the legal definition of a fertilizer, therefore, seaweed products are marketed as soil amendments or biostimulants [115].

Impact of Seaweed-based Amendments on Nutrient Uptake. Changes in nutrient uptake from the application of SWE vary based on the crop being grown and the nutrient status of the plants and soil at the time of application. SWE from the species Kappaphycus alvarezii resulted in significant increases in $\mathrm{N}, \mathrm{P}, \mathrm{K}$, and $\mathrm{S}$ uptake in soybeans when 49.75-97.5 L SWE/ha was applied foliarly at vegetative and flowering stages [116]. K, Fe, and Cu uptake increases were observed in olive trees treated with two wintertime applications of $17.5 \mathrm{ml}$ SWE/tree [117]. In a study by Crouch (1990), $12 \mathrm{ml}$ of foliar-applied SWE/plant resulted 
in increases of lettuce leaf $\mathrm{Ca}, \mathrm{K}$, and $\mathrm{Mg}$ concentrations by $52 \%, 46 \%$, and $37 \%$, respectively, as compared to control plants receiving no SWE [112]. The concentrations of $\mathrm{Ca}, \mathrm{K}$, and $\mathrm{Mg}$ in the lettuce leaves were approximately 10 times greater than their respective concentrations in the SWE [112]. However, SWE had no influence on $\mathrm{Ca}, \mathrm{Mg}$, or K concentrations in leaves of nutrient-stressed lettuce [112]. Beckett (1990) observed that SWE resulted in increased Zn uptake of tomato seedlings grown in macronutrient deficient conditions, but did not significantly affect $\mathrm{Zn}$ uptake when macronutrients were sufficient [118]. Cu uptake was increased in nutrient deficient grapevines with four foliar applications of SWE at 15 day intervals during shoot growth [119]. Greenhouse-grown Sangiovese grapevines treated foliarly with a combination of 0.1\% SWE and a 9-5-4 synthetic fertilizer twice a week for two months had increased $\mathrm{N}, \mathrm{P}, \mathrm{K}$, and $\mathrm{Mg}$ leaf concentrations, $\mathrm{N}$ and $\mathrm{P}$ shoot concentrations, and $\mathrm{P}$ and $\mathrm{K}$ root concentrations as compared to fertilized and unfertilized vines receiving no SWE [120].

Impact of Seaweed on Yield and Quality. Seaweed-based amendments can increase crop yield and quality parameters. SWE application resulted in greater root-to-shoot ratios as compared to untreated control in maize [121], tomato [122], and wheat plants [123]. Koo (1988) found that 3 post-bloom foliar applications of $4.68 \mathrm{~L} \mathrm{SWE} / \mathrm{ha}$ resulted in greater orange yields in 2 out of 3 study years [124]. Additional crops for which increased yields from seaweed-based amendment application have been observed include lettuce [113], spinach [125], soybean [116], olives [117], potato [126], strawberries [127], watermelons [128], and beans [107, 129]. Orange trees receiving 3 post-bloom foliar applications of 4.68 L SWE/ha had increased rind color intensity and a decreased number of green fruits as compared to the untreated control [124]. Olive trees treated with two wintertime 
applications of $17.5 \mathrm{ml} \mathrm{SWE/tree} \mathrm{developed} \mathrm{color} \mathrm{sooner} \mathrm{than} \mathrm{untreated} \mathrm{trees} \mathrm{[117].} \mathrm{Foliar}$ SWE applications resulted in greater total phenolics in carrots [130] and cucumbers [131]. SWE typically does not influence TSS, pH, or TA of with strawberries [127], watermelons [128], oranges [132], or mandarins [124]. Thompson Seedless table grapes fertigated with 2.34 and 3.5 L/ha SWE pre-bloom, post-bloom, or at phase I of berry development had significantly greater fruit yield, berry size, and cluster weight than control grapes [133]. Eight foliar applications of $2 \mathrm{~L} / \mathrm{ha}$ SWE between bloom and phase III of berry development resulted in increased table grape fruit yield, berry weight, cluster weight, rachis length, and percentage of first class graded clusters as compared to untreated control grapevines [134]. While SWE application did not result in changes in TSS, $\mathrm{pH}$, or TA as compared to untreated fruit in several table grape experiments [133-135], Kok (2004) found that three foliar SWE applications between pre-bloom and phase I of berry development resulted in greater TA and higher tannin concentrations as compared to untreated control grapevines [136]. Tempranillo grapes fertigated with $20 \mathrm{~L} / \mathrm{ha}$ of a grain-based biostimulant with a similar PGR profile as SWE resulted in juice with 22\% greater total phenolics, $70 \%$ greater total anthocyanins, and higher chroma intensity than juice from untreated grapes [137]. However, in many studies, SWE applied at the manufacturers' recommended rates resulted in no significant effects on yield or quality parameters of crops, including onions [138], barley [139], wheat [140], tomatoes [94, 97], mandarins [124, 132], strawberries [141], sweet peppers, broccoli, and lettuce [96].

Impact of Seaweed-based Amendments in Stressed Conditions. The ability of seaweed to increase yields during times of drought stress might be related to their ability to induce drought and heat stress tolerance in crops [120, 123, 142]. Increased heat and drought 
tolerance in creeping bentgrass as compared to untreated control plants was observed with foliar applications of $0.5 \mathrm{~kg} \mathrm{SWE} / \mathrm{ha}$ [142]. Soil drench applications of SWE applied at a rate of 1:250 resulted in increased wheat root growth during vegetative growth in droughtstressed and well-watered conditions, whereas SWE applied at a rate of 1:750 resulted in increased straw and grain yields, regardless of water status or growth stage [123]. Sangiovese grapevines treated with 4 applications of SWE during shoot growth had 25\% greater vegetative yields, less-negative midday leaf water potential values, and faster recovery from drought stress to full photosynthetic capacity than non-treated grapevines upon rehydration [120].

Seaweed-based amendments can also increase yields during times of nutrient stress, but results are highly dependent on the crop and the nutrient status of the plant at the time of application. When nutrient-stressed and sufficiently-fertilized beans were applied foliarly with SWE, the treatment resulted in improved yields in all nutrient status treatments as compared to untreated beans, with greater yield increases observed in the more nutrient-stressed treatments [129]. Greenhouse cucumbers treated with SWE had greater yields and root-to-shoot ratios than untreated cucumbers [143]. $100 \mathrm{ml}$ of $0.25 \%$ SWE solution applied as a root drench to soils with moderate and severe $\mathrm{K}$ deficiencies resulted in increased grain yield and root mass, though SWE had no effect on wheat grain yield or root mass in K sufficient soil [114]. However, yields of lettuce grown in nutrientstressed conditions were not significantly affected by soil applications of $12 \mathrm{ml} \mathrm{SWE} /$ plant split between 3 applications [113].

SWE has also been shown to provide nematode and disease suppression. When comparing the effects of 4 soil-applied SWEs made from 4 different seaweed species on 
chili peppers, all 4 SWEs resulted in reductions in nematode populations by over $50 \%$ within 24 to 48 hours as compared to untreated chili peppers, leading to an overall decrease in root galling and penetration by nematodes in the SWE treatments [144]. Sultana (2008) also found that several species of fungi that cause root rot were less prevalent in the SWE treated chili peppers than the untreated chili peppers [144]. Whapham (1994) observed that tomato plants receiving root drenches of SWE had 94\% less nematode eggs after one generation as compared to control plants treated with water [145]. When surviving eggs were placed in a SWE solution, 34.9\% fewer nematode eggs hatched as compared to eggs in untreated water [145]. Three foliar applications of $0.2 \%$ SWE reduced Alternaria radicina and Botrytis cinerea infections in carrots by 57\% and 53.5\%, respectively [130]. Greenhouse cucumbers treated with foliar or root drench applications of 0.15 or $0.3 \mathrm{ml}$ of SWE at 3 10-day intervals had reductions in the severity of the fungal diseases Alternaria cucumerinum, Didymella applanata, Fusarium oxysporum, and Botrytis cinerea [146]. However, the SWE Marinure applied at the manufacturer's recommended rates had no impact on soil-borne diseases of tomatoes [94]. Six foliar applications of 1.68 L/ha SWE between early shoot growth and veraison resulted in a reduction in the number of powdery mildew infected table grape clusters by $41 \%$ as compared to untreated grapevines [135].

Conclusion. The use of marine extracts could have numerous potential benefits for grape production. Fish-based fertilizers could result in increased marketable yields by providing disease suppression. Both fish- and seaweed-based fertilizers could also improve nutrient uptake and provide small amounts of nutrients, which could then be used to improve minor nutrient deficiencies or reduce fertilizer inputs. By encouraging root growth, SWE could accelerate root system development in young vineyards. The endogenous GAs and 
cytokinins in SWE could lead to increased yields and in grapes, improving economic returns. Considering that synthetic ABA application has resulted in improved grape phenolics in numerous studies, the endogenous ABA in SWE has the potential to improve phenolics in grapes. Given that SWE has been shown to assist in plant growth during times of heat, drought, nutrient, and pest stress, their use could be beneficial to wine grapes that frequently undergo periods of stress during the growing season. SWE has shown success in suppressing nematodes and fungal diseases that commonly plague grapes such as Botrytis cinerea and powdery mildew. SWE might prevent disease by directly encouraging systemic resistance, or indirectly by extending the rachis, which will loosen the cluster and reduce the probability of infection. Taken together, this suggests that fish- and seaweedbased amendments have the potential to affect yield, nutrient uptake, and wine quality. The objective of this study is to evaluate how fish and seaweed extracts impact Syrah grape nutrient uptake, yield components, and harvest juice quality parameters.

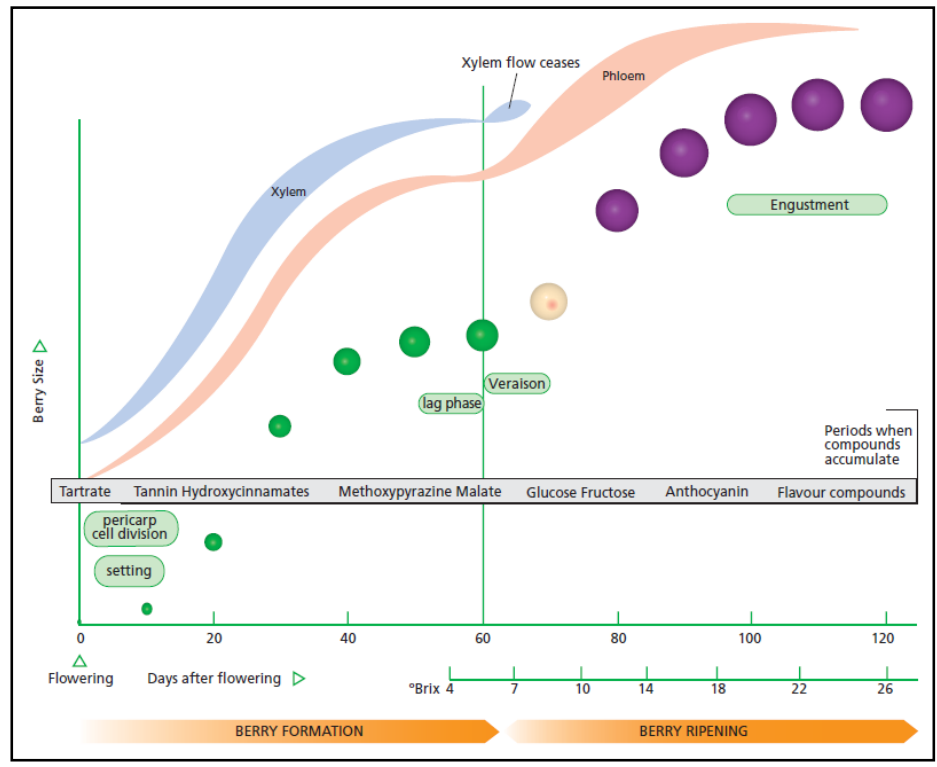

Figure 1.1. Grape berry development from flowering until harvest. From Kennedy (2002) [3]. 


\begin{tabular}{|c|c|c|c|c|c|c|}
\hline Rootstock & Parentage & $\begin{array}{l}\text { Relative scion } \\
\text { vigor }\end{array}$ & $\begin{array}{l}\text { Phylloxera } \\
\text { protection }\end{array}$ & $\begin{array}{l}\text { Root-knot } \\
\text { nematode } \\
\text { resistance }\end{array}$ & $\begin{array}{l}\text { Dagger } \\
\text { nematode } \\
\text { resistance }\end{array}$ & $\begin{array}{l}\text { Calcareous } \\
\text { soil } \\
\text { adaptation }\end{array}$ \\
\hline St. George & V. rupestris & high & high & low & low & Low \\
\hline $\begin{array}{l}\text { Riparia } \\
\text { Gloire }\end{array}$ & V. riparia & low & high & low & medium & low \\
\hline $1616 \mathrm{C}$ & V. riparia $\mathrm{x}$ V. solonis & low & high & high & medium & low \\
\hline $101-14 \mathrm{Mgt}$ & V. riparia $x$ V. rupestris & medium & high & medium & medium & low \\
\hline $3309 \mathrm{C}$ & V. riparia $x$ V. nupestris & $\begin{array}{l}\text { Low to } \\
\text { medium }\end{array}$ & high & low & low & low \\
\hline Schwarzmann & $V$. riparia $x$. nupestris & medium & high & high & high & medium \\
\hline Freedom & $\begin{array}{l}\text { V. } x \text { champinit, V. riparia, } \\
\text { V. labrisca, V. vinifera, } \\
\text { V. solonis complex hybrid }\end{array}$ & high & $\begin{array}{l}\text { medium to } \\
\text { high }\end{array}$ & high & high & medium \\
\hline Ramsey & $V \cdot \mathrm{x}$ champinii & high & high & high & low & medium \\
\hline $5 \mathrm{C}$ & $\begin{array}{l}V . \quad \text { berlandieri } \quad \mathrm{x} \quad V . \\
\text { riparia }\end{array}$ & medium & high & medium & medium & medium \\
\hline $5 \mathrm{BB}$ & $\begin{array}{l}\text { V. berlandieri } \times \quad V . \\
\text { riparia }\end{array}$ & medium & high & medium & low & medium \\
\hline $\mathrm{SO}_{4}$ & $\begin{array}{l}\text { V. berlandieri } \mathrm{x} \quad V . \\
\text { riparia }\end{array}$ & medium & high & medium & medium & medium \\
\hline $420 \mathrm{~A}$ & $\begin{array}{l}\text { V. berlandieri } \times \quad V . \\
\text { riparia }\end{array}$ & low & high & medium & low & medium \\
\hline $110 \mathrm{R}$ & $\begin{array}{l}V . \quad \text { berlandieri } \mathrm{x} \quad V . \\
\text { nupestris }\end{array}$ & medium & high & low & low & medium \\
\hline 1103P & $\begin{array}{l}\begin{array}{l}V . \quad \text { berlandieri } \\
\text { nupestris }\end{array} \\
\text { n }\end{array}$ & high & high & medium & low & medium \\
\hline Boemer & $V$. cinerea $\mathrm{x} V$. riparia & medium & high & high & high & low \\
\hline Gravesac & $\begin{array}{l}\text { V. riparia, } V \text {. nupestris, } \\
\text { V. berlandieri } \\
\text { complex hybrid }\end{array}$ & low & high & low & $\begin{array}{l}\text { (information } \\
\text { not } \\
\text { available) }\end{array}$ & low \\
\hline $\begin{array}{ll}41 & B \\
\text { Millardet } & \end{array}$ & $\begin{array}{l}\begin{array}{l}V . \quad \text { vimifera } \\
\text { berlandieri }\end{array} \\
\mathrm{x}\end{array}$ & medium & medium & low & low & very high \\
\hline Fercal & $\begin{array}{l}\text { V. vinifera, V. berlandieri } \\
\text { complex hybrid }\end{array}$ & $\begin{array}{l}\text { medium to } \\
\text { high }\end{array}$ & medium & medium & $\begin{array}{l}\text { (information } \\
\text { not } \\
\text { available) }\end{array}$ & very high \\
\hline 039-16 & $\begin{array}{l}\text { V. vinifera } \times \mathrm{V} \text {. } \\
\text { rotundifolia }\end{array}$ & high & high & low & high & Low \\
\hline
\end{tabular}

Table 1.1. Common grapevine rootstock parentage and characteristics. From Cousins (2005) [147].

Table 1.2. Total foliar $\mathrm{N}, \mathrm{P}, \mathrm{K}$ (\% dry weight) and $\mathrm{NH}_{4}{ }^{+}, \mathrm{NO}_{3}{ }^{-}, \mathrm{Zn}$, and $\mathrm{B}$ (ppm dry weight) of 12 wine grape cultivars. From Christensen et al. (1984) [54].

\begin{tabular}{cccccccc}
\hline Cultivar & $\begin{array}{c}\text { Total } \\
\mathbf{N}(\%)\end{array}$ & $\begin{array}{c}\mathbf{N O}^{-} \\
(\mathbf{p p m})\end{array}$ & $\begin{array}{c}\mathbf{N H}^{+} \\
\mathbf{p p m}\end{array}$ & $\begin{array}{c}\mathbf{P} \\
(\boldsymbol{\%})\end{array}$ & $\begin{array}{c}\mathbf{K} \\
(\boldsymbol{\%})\end{array}$ & $\begin{array}{c}\mathbf{Z n} \\
(\mathbf{p p m})\end{array}$ & $\begin{array}{c}\mathbf{B} \\
(\mathbf{p p m})\end{array}$ \\
Sauvignon blanc & 3.51 & 913 & 2144 & 0.54 & 1.05 & 32.0 & 69.5 \\
Petite Sirah & 3.42 & 947 & 995 & 0.38 & 1.02 & 25.5 & 48.0 \\
Chenin blanc & 3.35 & 1130 & 1498 & 0.47 & 1.25 & 35.5 & 48.5 \\
Zinfandel & 3.31 & 480 & 1258 & 0.33 & 1.13 & 28.0 & 39.0 \\
Rubired & 3.25 & 627 & 1413 & 0.46 & 1.35 & 31.5 & 64.5 \\
French Colombard & 3.13 & 549 & 998 & 0.42 & 0.89 & 21.0 & 51.0 \\
Barbera & 3.06 & 460 & 544 & 0.34 & 1.02 & 23.5 & 42.0 \\
Carignane & 3.03 & 487 & 811 & 0.23 & 1.48 & 30.0 & 41.0 \\
Grenache & 3.00 & 1060 & 1637 & 0.36 & 0.90 & 25.5 & 61.5 \\
Semillon & 2.98 & 600 & 1452 & 0.39 & 0.78 & 18.0 & 63.5 \\
Ruby Cabernet & 2.86 & 410 & 691 & 0.27 & 1.30 & 27.5 & 48.0 \\
Salvador & 2.81 & 270 & 447 & 0.31 & 0.53 & 14.0 & 56.0 \\
\hline
\end{tabular}




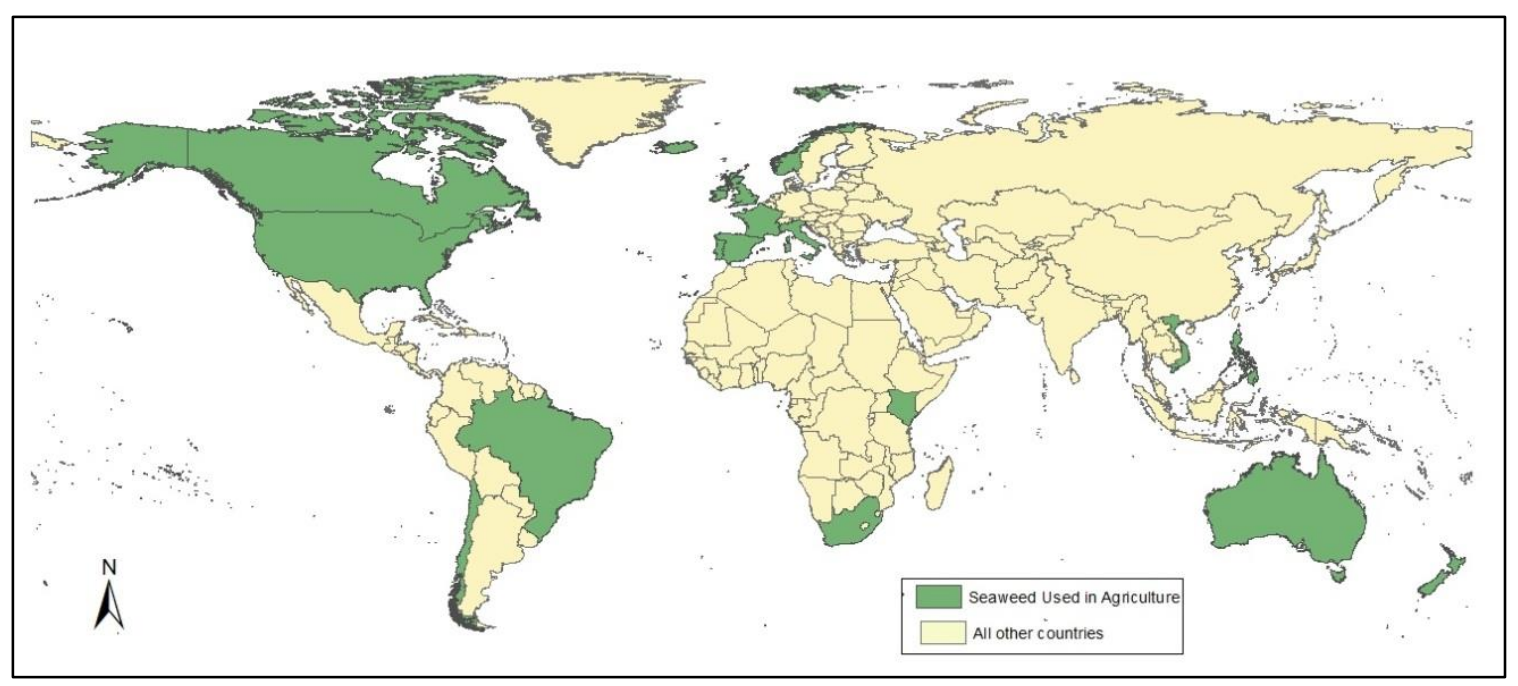

Figure 1.2. Countries where agricultural use of seaweed has been documented. Adapted from Zemke-White and Ohno (1999) [100]. 


\section{CHAPTER 2 \\ MATERIALS AND METHODS}

Site description and cultural methods. All experiments were conducted at the Trestle Vineyard on the California Polytechnic State University campus in San Luis Obispo, CA $\left(35^{\circ} 19^{\prime} \mathrm{N}, 120^{\circ} 41^{\prime} \mathrm{W}\right.$; elevation $\left.100 \mathrm{~m}\right)$. All vines were of the cultivar Syrah (clone 877), trained to a Smart-Dyson trellis system with $1.52 \mathrm{~m}$ by $2.44 \mathrm{~m}$ row spacing in Montmorillinite clay soil. Vines were pruned to two buds per spur on 10 March 2009, 5 March 2010, and 13 February 2011. Shoots were thinned to 2 shoots per spur before bloom on 19 May 2009, 8 June 2010, and 28 May 2011.

Fertigation experiment. Vines were grafted on Schwarzmann, a medium-vigor rootstock [36]. Deionized water, fish extract (Neptune's Harvest, Gloucester, ME, USA; 2-4-1), seaweed extract (Neptune's Harvest; 0-0-1), or fish/seaweed extract blend (Neptune's Harvest; 2-3-1) was applied during irrigation at full berry set (12 June 2009, 6 July 2010, and 21 June 2011) and except in 2011, at the onset of veraison (3 August 2009, 20 August 2010) using a randomized complete block design (RCBD) with 4 blocks (Figure 2.1 and Table 2.1). Each experimental unit was composed of three treated data vines with a treated buffer vine on each side and an untreated buffer vine on each end. At each application time, each data vine and treated buffer vine received $420 \mathrm{ml}$ per year of a 20:1 dilution of the fish extract, seaweed extract or fish/seaweed extract blend fertilizer in water (the per vine equivalent of the manufacturer's recommended 112 L/ha/year split into two doses) or 420 $\mathrm{ml}$ of water (control) underneath the drip emitter. In 2011, all data was collected prior to veraison; therefore, treatments were applied only at berry set, resulting in an overall application rate of (56 L/ha/year) (Table 2.1). 
Foliar fertilizer experiment. Vines were grafted on 420A, a low-vigor rootstock [36]. A RCBD with 6 blocks and 4 treatments was utilized (Figure 2.2 and Table 2.1), with each block containing one treated data vine per treatment and an untreated buffer vine between each data vine. Using a calibrated manual backpack sprayer (SB415 Professional, Shindaiwa, Lake Zurich, IL, USA), each data vine was treated foliarly at berry set (21 June 2011), with $2121 \mathrm{ml}$ of solution containing the same fish, seaweed or fish/seaweed blend fertilizers utilized in the soil fertigation experiment diluted with water at a rate of 100:1 (the per vine equivalent of the manufacturer's recommended $112 \mathrm{~L} / \mathrm{ha} /$ year split into two doses) or $2121 \mathrm{ml}$ of water (control). In 2011, all data was collected prior to veraison, therefore, only half of the manufacturer's recommended application rate was applied that year (Table 2.1).

Photosynthesis and stomatal conductance. To determine if the ABA in the seaweed extract or fish/seaweed extract blend applications had an effect on net photosynthesis and stomatal conductance, a portable photosynthesis system (LI-6200, Li-Cor, Inc., Lincoln, NE, USA) attached to an infrared gas analyzer (LI-6250, Li-Cor, Inc.) was used. A completely randomized design with 3 treatments and 6 replications was utilized. Vines were fertigated on 3 September 2009 with a $420 \mathrm{ml}$ solution of a 20:1 dilution of seaweed extract or fish/seaweed extract blend, or $420 \mathrm{ml}$ of water. Thirty minutes after application, 3 leaves from each vine were enclosed in a $4 \mathrm{~L}$ plastic chamber connected to the infrared gas analyzer that measured the change in carbon dioxide and relative humidity for $60 \mathrm{~s}$. After all of the readings were completed, leaf areas were input into the portable photosynthesis system computer, which calculated net photosynthetic rate and stomatal conductance based on net carbon dioxide exchange and relative humidity, respectively. 
Data collection. In 2009, all of the experimental units in the fertigation experiment were harvested on 21 September into separate bins and weighed with a digital scale (CD-11, Ohaus Corporation, Parsippany, NJ, USA). Berries were removed from 6 randomly selected clusters per bin, refrigerated overnight, and shipped on dry ice to ETS Laboratories (St. Helena, CA, USA) for phenolics testing. After the berries were slightly macerated, the grape must was heated and supplemented with $12 \%$ ethanol to simulate the extraction that occurs during the wine making process. Tannin and anthocyanin content were quantified using reverse phase analysis by a High Performance Liquid Chromatograph (1100, Agilent Technologies, Santa Clara, CA, USA). Twenty berries from 5 randomly selected clusters per bin were removed from each rachis. The total weight of the berries was determined with a digital gram scale (P-2002, Denver Instrument, Bohemia, NY, USA) and divided by 100 to determine the average berry weight of each experimental unit. The berries were then crushed to collect harvest juice samples for each experimental unit, from which TSS, $\mathrm{pH}$, and TA were determined. TSS was measured with a manual refractometer (LR45227, Milton Roy Company, Ivyland, PA, USA). The $\mathrm{pH}$ was determined with a digital $\mathrm{pH}$ meter (Fisher Scientific, Pittsburgh, PA, USA). To determine TA, a $10 \mathrm{ml}$ juice sample was diluted with $90 \mathrm{ml}$ of deionized water and titrated with $0.1333 \mu \mathrm{mol} / \mathrm{L} \mathrm{NaOH}$ to a $\mathrm{pH}$ of 8.2. The amount of $\mathrm{NaOH}$ solution required to titrate to a $\mathrm{pH}$ of 8.2 was multiplied by 1000 to calculate TA.

It was not possible to obtain 2010 harvest data. On 5 March 2010, pruning weights of the data vines in each experimental unit were determined using a digital scale (CD-11, Ohaus Corporation). For each experimental unit, the total weight of the clusters measured 
during the 2009 harvest was divided by the weight of the pruned canes to calculate the Ravaz Index.

For both the 2011 fertigation and foliar fertilizer experiments, all clusters were harvested upon full bunch closure on 1 August 2011 into separate bins by experimental unit. The clusters were weighed with a digital scale (UW4200 H, Shimadzu, Kyoto, Japan). Twenty berries from 5 randomly selected clusters from each experimental unit were weighed with the same digital scale and divided by 100 to calculate average berry weights. Rachis length was measured from the first berry-bearing stem to the end of the last pedicle. To estimate 2011 harvest yield, the 2011 fruit yields per vine and cluster weights were multiplied by 2 , based on the widely used multiplier of " 2 " used to project harvest yields based on lag phase berry weights [1]. Sixty leaves per experimental unit that were opposite the first cluster on each shoot were removed from the vines, separated into petioles and leaf blades, and submitted to Fruit Growers Laboratory (Santa Paula, CA, USA) to determine nutrient concentration. All plant material was washed, oven-dried, and subjected to one of three analyses. Total leaf $\mathrm{N}$ and petiole $\mathrm{NO}_{3}^{-}$were determined using the Dumas Combustion Method [148] and the Cadmium Reduction Method [149, 150], respectively (Appendix). Ash extractions [151] (Appendix) were used to determine all remaining measured macro- and micronutrients $(\mathrm{P}, \mathrm{K}, \mathrm{Ca}, \mathrm{Mg}, \mathrm{Zn}, \mathrm{Fe}, \mathrm{Mn}, \mathrm{B}$, and $\mathrm{Cu})$.

Statistical analyses. All statistical procedures were performed with SAS statistical software (SAS 9.1, SAS Institute, Inc., Cary, NC, USA) and Minitab 16 statistical software (Minitab Inc., State College, PA, USA). The response variables and residuals of all datasets were analyzed using Levene's test of equality of variance and the Shapiro-Wilk test for normality. The 2009 cluster weight dataset required a log transformation to pass Levene's 
test of equality of variance. Treatment differences were determined using the General Linear Model with post-hoc analyses conducted using Tukey's Studentized multiplecomparison procedure with a family error rate of $\alpha \leq 0.05$ or Dunnett's two-tailed $t$-test at $\alpha \leq 0.05$, which allows for comparisons of each treatment with the control.

To evaluate whether the disease presumed to be leaf-roll had a significant effect on 2009 harvest juice quality parameters and yield components in the fertigation blocks, $t$ tests for all harvest juice quality parameters and yield component variables were run between experimental units with no visual signs of disease (all of block 1 and block 4, experimental units 5 and 6 in block 2, and experimental units 11 and 12 in block 3), and those with signs of stunting (experimental units 7-10 in blocks 2 and 3). An ANOVA was run for all variables using only the non-diseased experimental units for analysis. 


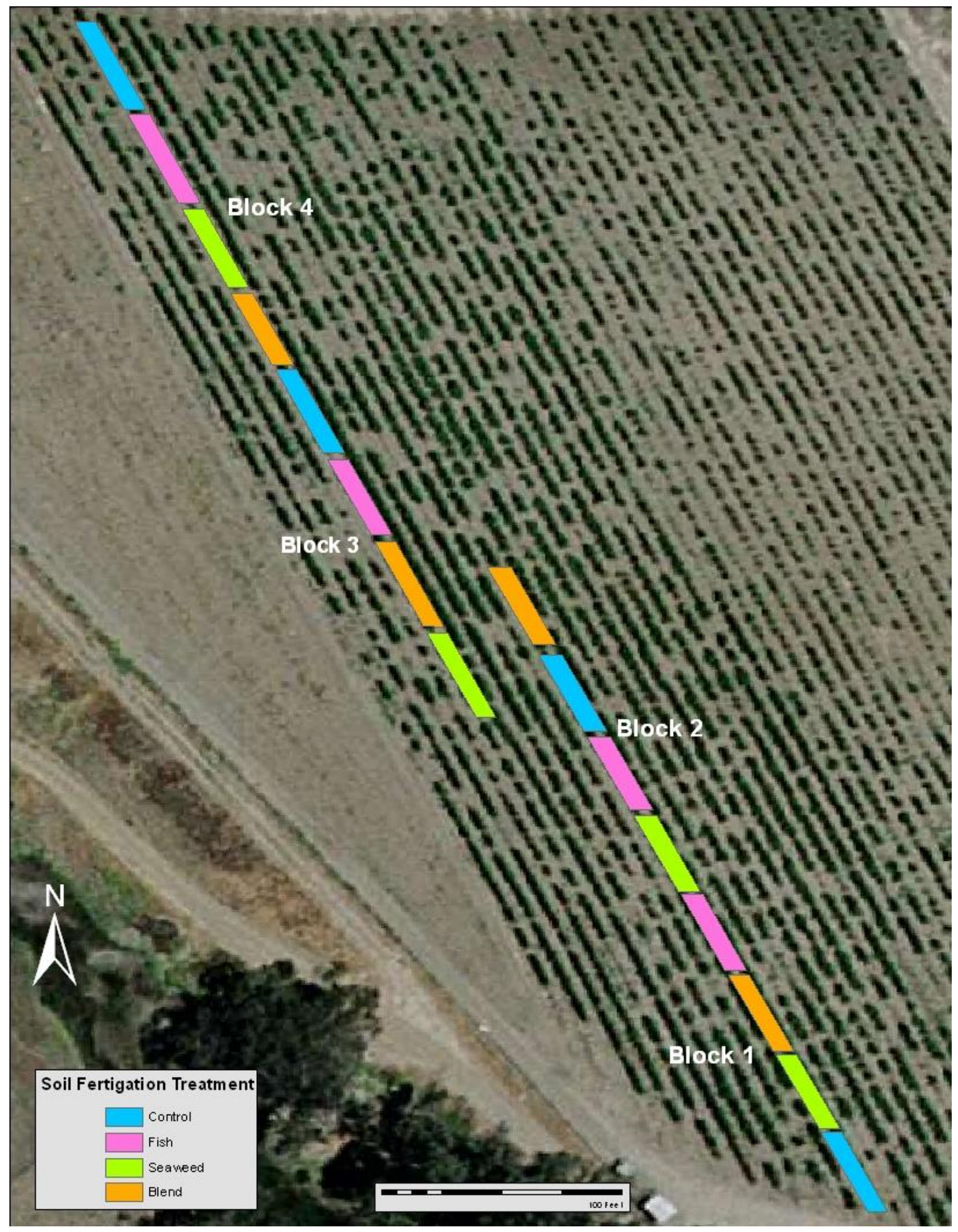

Figure 2.1. Map of the fertigation experiment conducted using Syrah vines on Schwarzmann rootstock at the Trestle Vineyard, California Polytechnic State University, San Luis Obispo, CA. Treatments were applied to 5 vines per treatment per block at berry set of 2009, 2010, and 2011, and at veraison in 2009 and 2010. Control = water; Fish = fish extract; Seaweed $=$ seaweed extract; Blend $=$ fish/seaweed extract blend. 


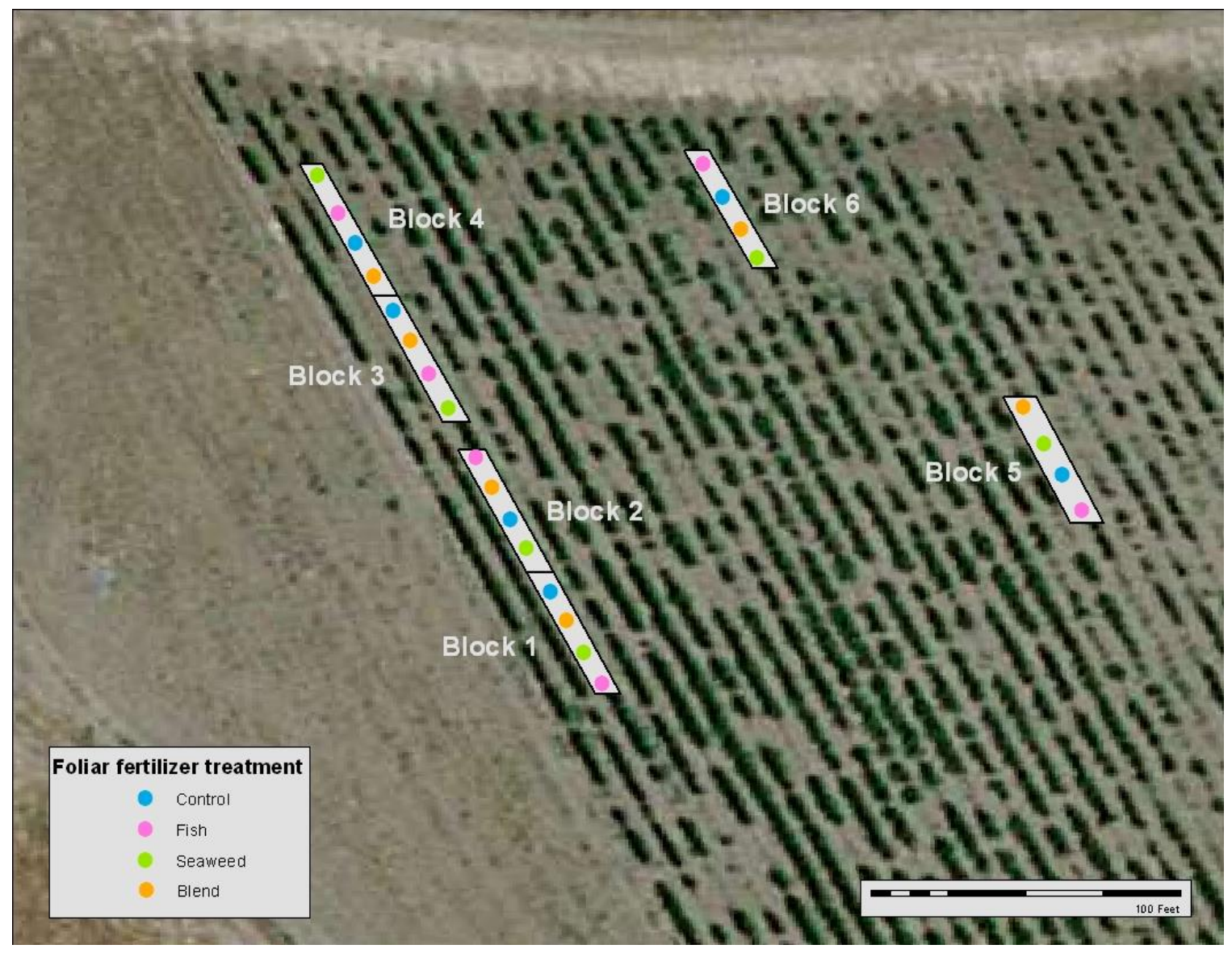

Figure 2.2. Map of the foliar fertilizer experiment conducted using Syrah vines on 420A rootstock at the Trestle Vineyard, California Polytechnic State University, San Luis Obispo, CA. Treatments were applied by foliar application to individual vines at berry set in 2011. Control = water; Fish $=$ fish extract; Seaweed $=$ seaweed extract; Blend = fish/seaweed extract blend.

Table 2.1. Total amount of macronutrients $(\mathrm{kg} / \mathrm{ha} / \mathrm{yr})$ applied in 2009 and 2010 by soil fertigation and in 2011 by soil fertigation or foliar application to Syrah vines at the Trestle Vineyard, California Polytechnic State University, CA. Control $=$ water; Fish $=$ fish extract, Seaweed $=$ seaweed extract; Blend $=$ fish/seaweed extract blend.

\section{Nutrients $(\mathrm{kg} / \mathrm{ha} / \mathrm{year})$}

\begin{tabular}{cccccccc} 
Treatment & \multicolumn{1}{c}{ Applied in 2009 or 2010 } & \multicolumn{3}{c}{ Applied in $\mathbf{2 0 1 1}$} \\
& $\mathbf{N}$ & $\mathbf{P}$ & $\mathbf{K}$ & $\mathbf{N}$ & $\mathbf{P}$ & $\mathbf{K}$ \\
Control & 0.00 & 0.00 & 0.00 & 0.00 & 0.00 & 0.00 \\
Fish & 2.40 & 3.10 & 0.15 & 1.20 & 1.55 & 0.08 \\
Seaweed & 0.00 & 0.00 & 0.15 & 0.00 & 0.00 & 0.08 \\
Blend & 1.81 & 2.32 & 0.15 & 0.91 & 1.16 & 0.08
\end{tabular}




\section{CHAPTER 3}

RESULTS

Harvest juice quality parameters and yield components. In the 2009 fertigation experiment, no significant treatment differences were detected between treatments in berry juice TSS ( ${ }^{\circ}$ Brix), $\mathrm{pH}$, TA $(\mathrm{g} / 100 \mathrm{ml})$, sugar-to-acid ratio (TSS: TA), anthocyanin concentration $(\mathrm{mg} / \mathrm{L})$, tannin concentration $(\mathrm{mg} / \mathrm{L})$, or anthocyanin-to-tannin ratio (Table 3.1). Additionally, no significant differences were detected in clusters per vine, berries per cluster, cluster weight $(\mathrm{g})$, average berry weight $(\mathrm{g})$, fruit yield per vine $(\mathrm{kg})$, vegetative yield per vine (kg), or Ravaz Index between soil fertigation treatments (Table 3.2). In 2011, soil fertigation (Table 3.3) and foliar fertilizer (Table 3.4) applications did not have significant effects on fruit yield per vine $(\mathrm{kg})$, clusters per vine, berries per cluster, cluster weight $(\mathrm{g})$, average berry weights $(\mathrm{g})$, or rachis length $(\mathrm{mm})$.

When soil fertigation was tested against time between 2009 and 2011, significant differences were found in yield components (Table 3.5). Clusters per vine and berries per cluster were significantly higher in 2009 than in $2011(p \leq 0.01)$. There were no significant differences between fruit yield per vine $(\mathrm{kg})$ in 2009 or estimated fruit yield per vine $(\mathrm{kg})$ in 2011. However, 2011 estimated harvest cluster weights (g) and estimated average berry weights (g) were significantly greater than 2009 cluster weights (g) and average berry weights $(\mathrm{g})$ at harvest $(p \leq 0.01)$. The fish/seaweed extract blend treatments had significantly more clusters per vine than the fish extract treatment; however neither treatment resulted in a significantly different number of clusters per vine than seaweed extract or control (Tukey's Studentized multiple-comparison procedure at $\alpha \leq 0.05$ or Dunnett's two-tailed $t$-test at $\alpha \leq 0.05$ ). There were no significant time by treatment interactions for any yield component. 
Nutrient uptake. The soil fertigation fish/seaweed extract blend treatment resulted in significantly greater leaf N (\%) than the seaweed extract treatment (Tukey's Studentized multiple-comparison procedure at $\alpha \leq 0.05$; Table 3.6). The seaweed extract foliar treatment resulted in significantly greater leaf $\mathrm{N}(\%)$ than the foliar fish/seaweed extract blend treatment (Tukey's Studentized multiple-comparison procedure at $\alpha \leq 0.05$; Table 3.7). However, none of the treatments resulted in significant differences in leaf $\mathrm{N}(\%)$ as compared to the control (Dunnett's two-tailed $t$-test at $\alpha \leq 0.05$ ). There was a marginally significant increase in petiole $\mathrm{Cu}(\mathrm{ppm})(p=0.07)$ in the fertigation experiment; however, there were no significant differences detected by Tukey's Studentized multiple-comparison procedure at $\alpha \leq 0.05$ or Dunnett's two-tailed $t$-test at $\alpha \leq 0.05$. Marginally significant increases in $\mathrm{Cu}$ concentration in response to seaweed extract fertigation as compared to all other fertigation treatments were detected with Dunnett's two-tailed $t$-test at $\alpha \leq 0.15$. There were no other significant differences in petiole nutrient content in either the foliar or fertigation experiment (Tables 3.6 and 3.7). All of the experimental units in 2011 were found to be deficient in total leaf $\mathrm{N}(\%)$ based on the critical values set forth by Christensen [58]. Some of the samples were deficient in petiole $\mathrm{NO}_{3}{ }^{-}, \mathrm{P}$, and/or $\mathrm{K}$ [58]. Many of the experimental units were low or deficient in petiole Fe [58]. None of the experimental units were deficient in $\mathrm{Ca}, \mathrm{Mg}, \mathrm{Zn}, \mathrm{Mn}$, or $\mathrm{Cu}$ (Tables 3.6 and 3.7).

Net Photosynthesis and Stomatal Conductance. Seaweed extract resulted in lower rates of net photosynthesis than the control and fish/seaweed extract blend $(p \leq 0.01$; Table 3.8), whereas fish/seaweed extract blend resulted in higher rates of net photosynthesis than control and seaweed treatments $(p \leq 0.01$; Table 3.8). Marine extract treatment did not significantly affect stomatal conductance. 
Impact of disease. Leaf roll virus appeared to be afflicting the Syrah block of the study site (personal observation, 21 September 2009). The symptoms included severely stunted shoots that were approximately $30-60 \mathrm{~cm}$ long and fruit that were still green at harvest. Fruit from vines showing no signs of disease had significantly higher $(p \leq 0.05)$ mean TSS $($ mean $=23.16)$ than fruit from diseased/stunted vines $($ mean $=20.47)$. The diseased vines also had a significantly higher mean tannin-to-anthocyanin ratio. However, when data from putative diseased vines were removed from statistical analyses of the fertigation treatments, there were still no significant differences in harvest juice quality parameters or yield components. 
Table 3.1. Effect of fertigation treatment on harvest juice TSS $\left({ }^{\circ} \mathrm{Brix}\right), \mathrm{pH}, \mathrm{TA}(\mathrm{g} / 100 \mathrm{ml})$, sugar-to-acid ratio (TSS: TA), tannins (mg/L), anthocyanins (mg/L), and anthocyanin: tannin ratio of Syrah grapes harvested on 21 September 2009 from Trestle Vineyard, California Polytechnic State University, San Luis Obispo, CA. Values are means \pm standard error $(n=16)$. Control $=$ water; Fish $=$ fish extract; Seaweed $=$ seaweed extract; Blend $=$ fish/seaweed extract blend.

\begin{tabular}{|c|c|c|c|c|c|c|c|}
\hline Treatment & TSS $\left({ }^{\circ}\right.$ Brix $)$ & pH & $\begin{array}{c}\text { TA } \\
(\mathrm{g} / 100 \mathrm{ml})\end{array}$ & TSS: TA & $\begin{array}{l}\text { Tannins } \\
(\mathrm{mg} / \mathrm{L})\end{array}$ & $\begin{array}{l}\text { Anthocyanins } \\
(\mathrm{mg} / \mathrm{L})\end{array}$ & $\begin{array}{c}\text { Tannins: } \\
\text { Anthocyanins }\end{array}$ \\
\hline Control & $23.55 \pm 0.53$ & $3.87 \pm 0.13$ & $0.52 \pm 0.03$ & $49.38 \pm 5.11$ & $639.5 \pm 21.9$ & $1475.3 \pm 44.9$ & $0.47 \pm 0.02$ \\
\hline Fish & $24.35 \pm 0.89$ & $3.86 \pm 0.03$ & $0.57 \pm 0.05$ & $47.83 \pm 5.23$ & $642.5 \pm 28.9$ & $1485.5 \pm 18.6$ & $0.43 \pm 0.02$ \\
\hline Seaweed & $23.33 \pm 0.33$ & $3.74 \pm 0.09$ & $0.53 \pm 0.03$ & $45.87 \pm 2.56$ & $563.3 \pm 16.9$ & $1515.0 \pm 11.4$ & $0.37 \pm 0.01$ \\
\hline Blend & $24.18 \pm 0.64$ & $3.68 \pm 0.13$ & $0.61 \pm 0.05$ & $42.54 \pm 3.26$ & $759.8 \pm 45.4$ & $1570.5 \pm 22.7$ & $0.48 \pm 0.02$ \\
\hline$F$ & 0.20 & 1.41 & 0.72 & 0.36 & 1.57 & 0.61 & 1.79 \\
\hline$p$ & 0.89 & 0.30 & 0.57 & 0.78 & 0.26 & 0.62 & 0.20 \\
\hline
\end{tabular}

Table 3.2. Effect of fertigation treatment on clusters per vine, berries per cluster, cluster weight (g), average berry weight (g), fruit yield per vine (kg), vegetative yield per vine $(\mathrm{kg})$, and Ravaz Index of Syrah grapes harvested on 21 September 2009 from Trestle Vineyard, California Polytechnic State University, San Luis Obispo, CA. Values are means \pm standard error $(n=16)$. Control $=$ water; Fish $=$ fish extract; Seaweed $=$ seaweed extract; Blend $=$ fish/seaweed extract blend.

\begin{tabular}{|c|c|c|c|c|c|c|c|}
\hline Treatment & $\begin{array}{c}\text { Clusters/ } \\
\text { Vine }\end{array}$ & $\begin{array}{l}\text { Berries/ } \\
\text { Cluster }\end{array}$ & $\begin{array}{c}\text { Cluster } \\
\text { Weight (g) }\end{array}$ & $\begin{array}{c}\text { Average } \\
\text { Berry } \\
\text { Weight (g) }\end{array}$ & $\begin{array}{c}\text { Fruit } \\
\text { Yield/Vine } \\
(\mathbf{k g})\end{array}$ & $\begin{array}{c}\text { Vegetative } \\
\text { Yield/Vine } \\
\text { (kg) }\end{array}$ & $\begin{array}{l}\text { Ravaz } \\
\text { Index }\end{array}$ \\
\hline Control & $31.8 \pm 1.4$ & $70.6 \pm 14.2$ & $43.48 \pm 3.64$ & $0.67 \pm 0.03$ & $1.43 \pm 0.17$ & $0.95 \pm 0.06$ & $1.45 \pm 0.12$ \\
\hline Fish & $27.1 \pm 0.3$ & $67.6 \pm 11.0$ & $42.28 \pm 2.92$ & $0.64 \pm 0.05$ & $1.18 \pm 0.07$ & $0.88 \pm 0.05$ & $1.36 \pm 0.12$ \\
\hline Seaweed & $24.3 \pm 0.9$ & $84.6 \pm 20.9$ & $51.63 \pm 0.81$ & $0.63 \pm 0.03$ & $1.69 \pm 0.13$ & $1.02 \pm 0.05$ & $1.69 \pm 0.12$ \\
\hline Blend & $34.9 \pm 0.3$ & $71.1 \pm 14.1$ & $37.04 \pm 0.58$ & $0.52 \pm 0.01$ & $1.29 \pm 0.07$ & $0.90 \pm 0.03$ & $1.47 \pm 0.07$ \\
\hline$F$ & 2.65 & 1.16 & 0.79 & 0.51 & 0.83 & 0.78 & 0.67 \\
\hline$p$ & 0.11 & 0.67 & 0.53 & 0.69 & 0.51 & 0.54 & 0.21 \\
\hline
\end{tabular}


Table 3.3. Effect of fertigation treatment on fruit yield per vine $(\mathrm{kg})$, clusters per vine, berries per cluster, cluster weight $(\mathrm{g})$, average berry weight $(\mathrm{g})$, and rachis length (mm) of Syrah grapes harvested on 1 August 2011 from Trestle Vineyard, California Polytechnic State University, San Luis Obispo, CA. Values are means \pm standard error $(n=16)$. Control $=$ water; Fish $=$ fish extract; Seaweed $=$ seaweed extract; Blend $=$ fish $/$ seaweed extract blend.

\begin{tabular}{ccccccc}
\hline & Fruit Yield/ & Clusters/ & Berries/ & $\begin{array}{c}\text { Average } \\
\text { Cluster } \\
\text { Veight (g) }\end{array}$ & $\begin{array}{c}\text { Berry } \\
\text { Weight (g) }\end{array}$ & $\begin{array}{c}\text { Rachis } \\
\text { Length (mm) }\end{array}$ \\
Treatment & $0.80 \pm 0.14$ & $21.0 \pm 1.8$ & $48.2 \pm 3.7$ & $35.46 \pm 3.39$ & $0.72 \pm 0.02$ & $130.0 \pm 1.6$ \\
Control & $0.60 \pm 0.06$ & $19.8 \pm 1.0$ & $51.7 \pm 2.7$ & $29.60 \pm 1.99$ & $0.57 \pm 0.02$ & $133.5 \pm 2.7$ \\
Fish & $0.77 \pm 0.06$ & $23.6 \pm 0.7$ & $56.8 \pm 3.0$ & $36.27 \pm 2.30$ & $0.64 \pm 0.02$ & $133.4 \pm 1.7$ \\
Seaweed & $0.70 \pm 0.04$ & $22.0 \pm 0.8$ & $49.8 \pm 1.2$ & $30.42 \pm 0.90$ & $0.61 \pm 0.02$ & $137.9 \pm 4.5$ \\
Blend & 0.65 & 0.81 & 0.81 & 0.53 & 1.89 & 0.29 \\
$\boldsymbol{F}$ & 0.60 & 0.52 & 0.52 & 0.68 & 0.20 & 0.83 \\
$\boldsymbol{p}$ & & &
\end{tabular}

Table 3.4. Effect of foliar treatment on fruit yield per vine $(\mathrm{kg})$, clusters per vine, berries per cluster, cluster weight $(\mathrm{g})$, average berry weight $(\mathrm{g})$, and rachis length $(\mathrm{mm})$ of Syrah grapes harvested on 1 August 2011 from Trestle Vineyard, California Polytechnic State University, San Luis Obispo, CA. Values are means \pm standard error $(n=24)$. Control $=$ water; Fish $=$ fish extract; Seaweed = seaweed extract; Blend = fish/seaweed extract blend.

\begin{tabular}{|c|c|c|c|c|c|c|}
\hline Treatment & $\begin{array}{l}\text { Fruit Yield/ } \\
\text { Vine (kg) }\end{array}$ & $\begin{array}{c}\text { Clusters/ } \\
\text { Vine }\end{array}$ & $\begin{array}{l}\text { Berries/ } \\
\text { Cluster }\end{array}$ & $\begin{array}{c}\text { Cluster } \\
\text { Weight (g) }\end{array}$ & $\begin{array}{c}\text { Average } \\
\text { Berry } \\
\text { Weight (g) }\end{array}$ & $\begin{array}{c}\text { Rachis } \\
\text { Length (mm) }\end{array}$ \\
\hline Control & $0.94 \pm 0.11$ & $28.5 \pm 2.0$ & $61.6 \pm 3.4$ & $30.73 \pm 1.67$ & $0.50 \pm 0.02$ & $121.0 \pm 2.3$ \\
\hline Fish & $0.55 \pm 0.07$ & $21.7 \pm 2.0$ & $55.6 \pm 3.8$ & $24.57 \pm 1.09$ & $0.46 \pm 0.02$ & $114.5 \pm 4.5$ \\
\hline Seaweed & $0.76 \pm 0.08$ & $24.2 \pm 1.9$ & $71.3 \pm 8.2$ & $30.67 \pm 1.86$ & $0.49 \pm 0.02$ & $122.3 \pm 1.9$ \\
\hline Blend & $0.76 \pm 0.09$ & $26.5 \pm 2.3$ & $67.3 \pm 5.5$ & $27.08 \pm 1.25$ & $0.44 \pm 0.03$ & $114.2 \pm 3.1$ \\
\hline$F$ & 1.14 & 0.68 & 0.57 & 1.17 & 0.76 & 0.92 \\
\hline$p$ & 0.37 & 0.58 & 0.64 & 0.35 & 0.53 & 0.45 \\
\hline
\end{tabular}


Table 3.5. Effect of fertigation by treatment, year, and treatment*year interaction on fruit yield per vine (kg), clusters per vine, berries per cluster, cluster weight $(\mathrm{g})$, and average berry weight (g) of Syrah grapes harvested on 21 September 2009 and 1 August 2011 from Trestle Vineyard, California Polytechnic State University, San Luis Obispo, CA. Values are means \pm standard error $(n=32)$. Control $=$ water; Fish $=$ fish extract; Seaweed = seaweed extract; Blend $=$ fish/seaweed extract blend.

\begin{tabular}{cccccc}
\hline Treatment & $\begin{array}{c}\text { Fruit Yield/ } \\
\text { Vine }(\mathbf{k g})\end{array}$ & $\begin{array}{c}\text { Clusters/ } \\
\text { Vine }\end{array}$ & $\begin{array}{c}\text { Berries/ } \\
\text { Cluster }\end{array}$ & $\begin{array}{c}\text { Cluster } \\
\text { Weight (g) }\end{array}$ & $\begin{array}{c}\text { Average Berry } \\
\text { Weight }(\mathbf{g})\end{array}$ \\
Control & $1.38 \pm 0.11$ & $25.13 \pm 1.48 \mathrm{ab}$ & $59.40 \pm 3.17$ & $57.18 \pm 4.41$ & $1.03 \pm 0.08$ \\
Fish & $1.17 \pm 0.06$ & $23.44 \pm 0.85 \mathrm{~b}$ & $59.64 \pm 2.34$ & $50.74 \pm 2.79$ & $0.89 \pm 0.06$ \\
Seaweed & $1.68 \pm 0.07$ & $28.02 \pm 1.17 \mathrm{ab}$ & $70.67 \pm 3.83$ & $62.05 \pm 3.11$ & $0.96 \pm 0.07$ \\
Blend & $1.35 \pm 0.05$ & $28.94 \pm 1.20 \mathrm{a}$ & $60.44 \pm 2.65$ & $48.94 \pm 2.53$ & $0.88 \pm 0.07$ \\
$\boldsymbol{F}$ & 1.73 & 3.27 & 1.29 & 1.25 & 1.49 \\
$\boldsymbol{p}$ & 0.19 & 0.04 & 0.30 & 0.32 & 0.24 \\
Year & & & & & \\
2009 & $1.39 \pm 0.08$ & $31.54 \pm 0.76 \mathrm{a}$ & $73.45 \pm 2.73 \mathrm{a}$ & $43.60 \pm 1.99 \mathrm{a}$ & $0.60 \pm 0.02 \mathrm{a}$ \\
2011 & $1.40 \pm 0.08$ & $21.22 \pm 0.80 \mathrm{~b}$ & $51.63 \pm 1.87 \mathrm{~b}$ & $65.86 \pm 3.12 \mathrm{~b}$ & $1.27 \pm 0.03 \mathrm{~b}$ \\
$\boldsymbol{F}$ & 0.00 & 53.27 & 20.81 & 17.00 & 144.93 \\
$\boldsymbol{p}$ & 0.96 & $<0.01$ & $<0.01$ & $<0.01$ & $<0.01$ \\
Treatment* & & & & & \\
Year & & & & & \\
$\boldsymbol{F}$ & 0.09 & 0.96 & 0.26 & 0.17 & 1.52 \\
$\boldsymbol{p}$ & 0.97 & 0.43 & 0.85 & 0.92 & 0.24 \\
\hline
\end{tabular}

a, b: Treatment means within the same column with different letters indicate significance at $\alpha \leq 0.05$ using Tukey’s Studentized multiple comparison procedure. 
Table 3.6. Petiole $\mathrm{NO}_{3}^{-}$(ppm dry weight), \% dry weight leaf blade $\mathrm{N}, \%$ dry weight petiole $\mathrm{P}, \mathrm{K}, \mathrm{Ca}$, and $\mathrm{Mg}$, and ppm dry weight petiole $\mathrm{Zn}$, Mn, Fe, B, and Cu of petioles and leaves harvested from fertigation-treated Syrah vines on 1 August 2011 at Trestle Vineyard, California Polytechnic State University, CA. Values are means \pm standard error $(\mathrm{n}=16)$. Control= water; Fish $=$ fish extract; Seaweed $=$ seaweed extract; Blend $=$ fish $/$ seaweed extract blend.

\begin{tabular}{|c|c|c|c|c|c|c|c|c|c|c|c|}
\hline Treatment & $\mathrm{NO}_{3^{-}}^{-}(\mathbf{p p m}$ & $\mathbf{N}(\%)$ & $\mathbf{P}(\%)$ & $\mathbf{K}(\%)$ & $\mathrm{Ca}(\%)$ & $\operatorname{Mg}(\%)$ & Zn (ppm) & Mn (ppm) & $\mathrm{Fe}(p p m)$ & B (ppm) & $\mathrm{Cu}(\mathbf{p p m})$ \\
\hline Control & $749 \pm 94$ & $2.36 \pm 0.03 \mathrm{ab}$ & $0.22 \pm 0.01$ & $3.32 \pm 0.27$ & $1.24 \pm 0.06$ & $0.57 \pm 0.04$ & $48.4 \pm 1.4$ & $49.0 \pm 1.9$ & $36.0 \pm 0.7$ & $34.1 \pm 0.7$ & $7.8 \pm 0.1$ \\
\hline Fish & $593 \pm 51$ & $2.31 \pm 0.05 \mathrm{ab}$ & $0.25 \pm 0.02$ & $3.98 \pm 0.05$ & $1.10 \pm 0.02$ & $0.54 \pm 0.01$ & $43.1 \pm 2.5$ & $52.3 \pm 2.9$ & $35.5 \pm 0.3$ & $39.3 \pm 1.1$ & $8.0 \pm 0.1$ \\
\hline Seaweed & $546 \pm 51$ & $2.19 \pm 0.04 a$ & $0.27 \pm 0.03$ & $3.38 \pm 0.27$ & $1.13 \pm 0.04$ & $0.58 \pm 0.02$ & $48.9 \pm 2.0$ & $56.8 \pm 2.9$ & $38.5 \pm 1.6$ & $36.4 \pm 1.2$ & $9.5 \pm 0.4^{*}$ \\
\hline Blend & $987 \pm 13$ & $2.57 \pm 0.04 b$ & $0.24 \pm 0.01$ & $3.47 \pm 0.07$ & $1.28 \pm 0.04$ & $0.65 \pm 0.06$ & $45.1 \pm 2.7$ & $52.0 \pm 3.7$ & $36.3 \pm 1.0$ & $36.6 \pm 1.2$ & $7.3 \pm 0.2$ \\
\hline$F$ & 2.0 & 3.75 & 0.23 & 0.85 & 1.58 & 0.72 & 0.34 & 0.83 & 0.37 & 1.18 & 3.29 \\
\hline$p$ & 0.18 & 0.05 & 0.87 & 0.50 & 0.26 & 0.57 & 0.79 & 0.51 & 0.78 & 0.37 & 0.07 \\
\hline
\end{tabular}

a, b: Treatment means within the same column with different letters indicate significance at $\alpha \leq 0.05$ using Tukey's Studentized multiple comparison procedure.

*: Treatment means within the same column with a * are significantly different from control level using Dunnett's two- tailed t-test at $\alpha \leq 0.15$.

Table 3.7. Petiole $\mathrm{NO}_{3}^{-}$(ppm dry weight), \% dry weight leaf blade N, \% dry weight petiole P, K, Ca, and Mg, and ppm dry weight petiole $\mathrm{Zn}$, Mn, Fe, B, and Cu of petioles and leaves harvested from foliar-treated Syrah vines on 1 August 2011 at Trestle Vineyard, California Polytechnic State University, CA. Values are means \pm standard error $(n=24)$. Control= water; Fish = fish extract; Seaweed = seaweed extract; Blend = fish/seaweed extract blend.

\begin{tabular}{|c|c|c|c|c|c|c|c|c|c|c|c|}
\hline Treatment & $\mathrm{NO}_{3}^{-}(\mathbf{p p m})$ & $\mathbf{N}(\%)$ & $\mathbf{P}(\%)$ & $\mathbf{K}(\%)$ & $\mathrm{Ca}(\%)$ & $\operatorname{Mg}(\%)$ & Zn (ppm) & Mn (ppm) & $\mathrm{Fe}(\mathrm{ppm})$ & B (ppm) & $\mathrm{Cu}(\mathbf{p p m})$ \\
\hline Control & $753 \pm 180$ & $2.32 \pm 0.04 \mathrm{ab}$ & $0.16 \pm 0.02$ & $1.92 \pm 0.16$ & $1.35 \pm 0.02$ & $0.82 \pm 0.03$ & $44.2 \pm 2.3$ & $43.3 \pm 2.5$ & $30.0 \pm 0.9$ & $37.5 \pm 0.9$ & $8.3 \pm 0.5$ \\
\hline Fish & $692 \pm 162$ & $2.29 \pm 0.05 \mathrm{ab}$ & $0.16 \pm 0.02$ & $2.62 \pm 0.03$ & $1.38 \pm 0.04$ & $0.70 \pm 0.05$ & $43.3 \pm 1.8$ & $42.3 \pm 3.0$ & $33.3 \pm 1.4$ & $36.2 \pm 0.9$ & $8.0 \pm 0.4$ \\
\hline Seaweed & $904 \pm 171$ & $2.50 \pm 0.04 b$ & $0.22 \pm 0.04$ & $3.15 \pm 0.27$ & $1.33 \pm 0.04$ & $0.70 \pm 0.04$ & $49.1 \pm 1.2$ & $51.2 \pm 2.1$ & $29.2 \pm 0.2$ & $41.4 \pm 1.6$ & $8.7 \pm 0.5$ \\
\hline Blend & $519 \pm 131$ & $2.22 \pm 0.02 \mathrm{a}$ & $0.18 \pm 0.01$ & $2.16 \pm 0.18$ & $1.30 \pm 0.02$ & $0.77 \pm 0.04$ & $47.1 \pm 2.6$ & $44.8 \pm 2.7$ & $30.2 \pm 0.4$ & $34.6 \pm 1.1$ & $8.0 \pm 0.3$ \\
\hline $\boldsymbol{F}$ & 1.76 & 3.55 & 0.92 & 1.92 & 0.12 & 0.49 & 0.67 & 0.61 & 1.03 & 1.76 & 0.13 \\
\hline$p$ & 0.20 & 0.04 & 0.45 & 0.17 & 0.95 & 0.70 & 0.58 & 0.62 & 0.41 & 0.20 & 0.94 \\
\hline
\end{tabular}

a, b: Treatment means within the same column with different letters indicate significance at $\alpha \leq 0.05$ using Tukey's Studentized multiple comparison procedure. 
Table 3.8. Net photosynthetic rate $\left(\mu \mathrm{mol} \mathrm{CO} \mathrm{C}^{-2} \mathrm{~s}^{-1}\right)$ and stomatal conductance $\left(\mathrm{mol} \mathrm{H}_{2} \mathrm{O} \mathrm{CO}_{2} \mathrm{~m}^{-2} \mathrm{~s}^{-1}\right)$ of Syrah grape leaves immediately after fertigation with water, seaweed extract, or fish/seaweed extract blend on 17 August 2009 at Trestle Vineyard, California Polytechnic State University, San Luis Obispo, CA. Values are means \pm standard error $(n=18)$. Control $=$ water; Seaweed $=$ seaweed extract; Blend $=$ fish $/$ seaweed extract blend.

Control
Seaweed
Blend
$\boldsymbol{F}$
$\boldsymbol{p}$

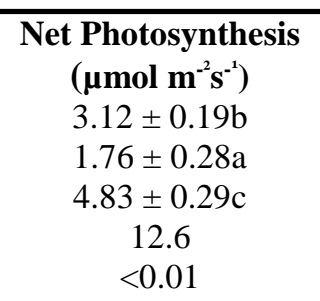
Stomatal Conductance ( $\mathrm{mol} \mathrm{H} \mathrm{H}_{2} \mathrm{~m}^{-2} \mathrm{~s}^{-1}$ )




\section{CHAPTER 4 \\ DISCUSSION AND CONCLUSION}

None of the marine extracts tested in the study reported herein resulted in significant differences in yield or harvest juice quality parameters of Syrah grapes as compared to the control. The only significant treatment difference for any yield component was that vines fertigated with fish/seaweed extract blend had significantly more clusters per vine than those fertigated with fish extract when the two years of yield data were combined. However, since fruit clusters were formed prior to fertigation in 2009 , the treatments could not have affected the number of clusters per vine in that year. High variability in the number of clusters per vine could have been due to inconsistencies in training and pruning prior to the experiment. Whereas clusters per vine and berries per cluster decreased significantly from 2009 to 2011, cluster weight and average berry weight increased significantly without significant differences in total fruit yield per vine between the 2 years. While it is possible that these differences are an artifact of having estimated cluster weight, yield per vine, and average berry weight in 2011, they seem more likely due to vine-yield compensation. As clusters per vine and berries per cluster declined, cluster and average berry weights increased to compensate for the reduced number of clusters and berries. This is in agreement with Kleiwer et al. (1983), who found that cluster thinning reduced the number of clusters but did not reduce yield relative to the non-cluster thinning treatments. In that experiment, the average cluster weight of the cluster thinning treatments was heavier than the average cluster weight of the non-cluster thinning treatment. 
Clusters per vine and berries per cluster were each significantly $(p \leq 0.01)$ higher in 2009 than in 2011 of the soil fertigation experiment. These differences could have been a result of variations in canopy management, including pruning [24], and/or vine growth from year to year, despite attempts to maintain consistent conditions. Climatic conditions, including a possible late-spring frost in April 2011, could have reduced the cluster count. On 8 April 2011, a low of $32.7^{\circ} \mathrm{F}$ was recorded at the California Irrigation System Management Information Service (CIMIS) weather station number 52, which is located $2.5 \mathrm{~km}$ from the study site [152]. Considering meso- and microclimatic variation between the study site and the weather station, it is possible that damaging sub-freezing temperatures occurred at the study site.

The lack of significant differences in yield components and harvest juice quality parameters could have been the result of the putative virus, which noticeably delayed ripening, leading to high variability in the means of these variables. The vines that were visually stunted, presumably due to a virus, had an average of $2.69^{\circ}$ Brix less than vines showing no visual signs of stunting. The reduced TSS in the fruit from the stunted vines is in agreement with the significantly greater tannin-to-anthocyanin ratio in the fruit from the stunted vines. Since the diseased fruit stayed green and under-ripe, there was a greater quantity of tannins relative to anthocyanins at harvest compared to properly ripened fruit that accumulated more anthocyanins. The greater tannin-to-anthocyanin ratio and reduced TSS in fruit from the stunted vines indicates that the virus may have significantly hindered fruit development in this experiment. The results of the study reported herein are consistent with results from previous studies in which virus pressures reduced the TSS of fruit from Albarino [10], Reisling [12], and Pinot Noir [11] grapevines. However, when diseased 
samples were excluded from statistical analyses in the study reported herein, no significant differences in yield and harvest juice quality parameters were detected.

With the exception of an increase in leaf $\mathrm{Cu}$ concentration in response to fertigation with seaweed extract, none of the marine extract treatments resulted in significant differences in petiole or leaf nutrient concentrations as compared to the control. That fertigation with seaweed extract resulted in a significant increase in $\mathrm{Cu}$ concentration as compared to the control was consistent with the findings of Turan (2004). However, the lack of any other significant change in leaf nutrient concentration in the study reported herein are in contrast with the findings of Mancuso et al. (2006). They found that uptake of $\mathrm{N}, \mathrm{P}, \mathrm{K}$, and $\mathrm{Mg}$ by Sangiovese grapevines increased significantly in response to foliar applications of SWE [120]. Fertigation with fish/seaweed extract blend resulted in significantly greater leaf $\mathrm{N}(\%)$ than the seaweed extract, whereas foliar applications of seaweed extract resulted in significantly more leaf $\mathrm{N}(\%)$ than the fish/seaweed extract blend. Since the fish/seaweed extract blend treatment added 1.81 more $\mathrm{kg} \mathrm{N} / \mathrm{ha} / \mathrm{yr}$ compared to the seaweed extract alone, it is possible that the additional $\mathrm{N}$ applied with the fish/seaweed extract blend fertigation was the cause of the increase in leaf $\mathrm{N}$ concentration. had the highest total $\mathrm{N}$ application but did not result in leaf $\mathrm{N}$ concentrations that were significantly different from those of any other treatment. There was less applied $\mathrm{N}$ in the foliarly applied seaweed extract than the fish/seaweed extract blend and fish extract treatments; however, the seaweed extract treatment only had significantly greater leaf $\mathrm{N}$ concentrations than the fish/seaweed extract blend treatment. However, it is important to note that all of the foliar-treated vines were on 420A rootstock, whereas fertigated vines were on Schwarzmann rootstock. Different rootstocks vary in there nutrient uptake patterns 
[36]. Therefore, it is not possible to determine whether if the treatment differences in leaf $\mathrm{N}$ concentration reported herein were due to differences in the compound applied, the application method (fertigation or foliar), or to the rootstock. Regardless, the effects of the marine extract treatments on leaf nutrient concentration were negligible.

The lack of significant effects on harvest juice quality parameters and yield components in response to marine extract applications in the study reported herein could have been due to the compounds low nutrient content. While TSS typically reduced as a result of $\mathrm{N}$ fertilization [4-9], some studies have reported no significant changes in TSS with higher $\mathrm{N}$ rates than were applied in the study reported herein $[61,63,64]$. Since $\mathrm{pH}$ and TA often have variable and inconsistent responses to $\mathrm{N}$ fertilizer application $[5-8,63$, 64], it is not surprising that the small quantities of $\mathrm{N}$ applied during the study reported herein did not result in detectable changes in $\mathrm{pH}$ or TA. Several studies with wine or table grapes have demonstrated that $\mathrm{N}$ applications that were orders of magnitude higher than those utilized in the study reported herein also failed to significantly affect fruit or vegetative yield $[63,64,71]$. $\mathrm{N}$ treatment of grapes has also been reported to increase fruit yields $[25,26,63,72]$, while in other studies $N$ treatment reduced fruit yields $[7,63,66$, 68]. However, the $\mathrm{N}$ application rates used in these studies were orders of magnitude higher than the $\mathrm{N}$ rates applied in the study reported herein. While working with the same marine extracts as those used in this study, Brown (2004) reported no significant effects on lettuce, broccoli or sweet pepper yields. Fish fertilizers also had no effect on crop yield in tomatoes $[94,97]$ or wheat [140]. Furthermore, SWE did not have a significant effect on yield or quality parameters of onions [138], barley [139], wheat [140], tomatoes [94, 97], mandarins $[124,132]$, or strawberries [141]. 
Marine extracts also have the potential to influence yield and harvest juice quality parameters due to their PGR content. Though ABA is not listed among the active ingredients in commercial marine extracts, Boyer [110] found that commercial SWEs contained 0.1 to $0.46 \mathrm{ppm}$ ABA. Based on these estimates, each of the fertigated vines in the study reported herein would have received 4.2 to $9.66 \mu \mathrm{g}$ ABA each year, with each foliar treated vine receiving approximately half of that amount. This amount of ABA is very small in comparison to the rates required to increase grape anthocyanin content. For example, $250 \mu \mathrm{g}$ of $\mathrm{ABA}$ applied directly to each grape cluster was required to significantly increase the anthocyanin content of Pinot Noir grapes [31]. The ABA rates applied to grapevines in similar ABA studies [28, 30, 32, 33] were also much higher than the amount of ABA received from the SWE in the study reported herein. Other PGRs present in marine extracts containing SWE, such as cytokinins and GAs, could also be responsible for altering yield components in crops, however these PGRs are also present in negligible amounts in SWEs compared to the rates required to significantly affect grape yield components and harvest juice quality parameters [27, 29, 34, 35, 49, 52].

In previously published experiments, TSS, $\mathrm{pH}$, and TA of grape berries have not been significantly affected by ABA applications [28, 30-33], which is consistent with the results of the study reported herein. Exogenously applied ABA can significantly increase color and anthocyanins in wine and table grapes [28, 30-33]. However, the most dramatic increases in color have been observed in color-poor table grape varieties such as Flame Seedless [32] and in grapes grown in hot climates [31-33] due to rapid anthocyanin biosynthesis early in phase III of berry growth [28]. While exogenous ABA applications can increase anthocyanin content in Flame Seedless table grapes by $800 \%$ compared to 
untreated controls [32], ABA-treated Merlot grapes had only 7\% more anthocyanins than untreated controls [55] and the anthocyanin content of ABA-treated Cabernet Sauvignon grapes was not significantly different that of control grapes when harvested late in phase III of berry growth [28]. Therefore, since ABA applications failed to increase anthocyanin content of Cabernet Sauvignon at harvest [28] and only marginally increased Merlot anthocyanin content [55], it would most likely have minimal effects on a high-anthocyanin cultivar such as Syrah.

Immediately after fertigation with seaweed extract or fish/seaweed extract blend, net photosynthesis changed significantly as compared to the control. Therefore, it is likely that the vine roots absorbed the marine extract treatments. These results are in contrast to Jeannin (1991), where foliarly applied SWE reduced stomatal conductance and transpiration rate in maize, but did not effect net photosynthesis [121]. The decreased rate of net photosynthesis as a result of seaweed extract fertigation could have occurred as a result of the product's putative ABA content. This is in agreement with Wang et al. (2004), who found that the application of $\mathrm{ABA}$ reduced net photosynthesis in creeping bentgrass. In the study reported herein, the fish/seaweed treatment resulted in increased net photosynthesis as compared to the control and seaweed treatments. This might have been due to the $\mathrm{N}$ in the fish/seaweed treatment. Increased net photosynthesis as a result of $\mathrm{N}$ application has been observed in Müller-Thurgau grapevines [23]. However, in the study reported herein, stomatal conductance was not significantly affected by either marine extract. The effects on net photosynthesis in the study reported herein were likely temporary, since yield and harvest juice quality parameters were not influenced by any fertigation treatment. 
Seaweed extracts have been used to successfully improve yield and quality parameters in a wide variety of crops $[107,113,116,117,121-132]$, including grapes [133136]. However, there have been numerous studies where seaweed extracts had no effect on yield or quality components $[94,96,97,124,132,138-141]$. The inconsistent findings could be due to multiple factors, including differences in species, cultivar, rootstock, application rate, seaweed source and species, soil characteristics, initial plant nutrient status, irrigation, and/or environmental conditions. For example, it is possible that Syrah could be less responsive to SWE application than Sangiovese or table grapes cultivars that are significantly affected by seaweed extract application, including increases in berry weight [133-135], fruit yield [133-135], TA [136], color [133], tannins [136], nutrient uptake $[119,120]$, vegetative yield [120], and drought stress tolerance [120]. To ascertain if the lack of effectiveness of the marine extracts tested in the study herein to increase the anthocyanin content is due to the extracts' low concentration of ABA, the cultivar used, or some other factor, it would be interesting to test the effectiveness of synthetic ABA applications to significantly increase anthocyanin content of Syrah fruit. More experiments with marine extracts are also needed in order to better understand how these products might be able to influence yield components, harvest juice quality parameters, and nutrient uptake.

Overall, there appears to be no beneficial or detrimental effects from applying marine extracts to Syrah grapes growing in cool-climates and heavy clay soils. While beneficial impacts have been observed in other experiments, the lack of significantly different results observed in this study suggest that the products utilized had little to no effect on harvest juice quality, yield components, or nutrient concentration. Conversely, if 
a grower wanted to use these products for another purported benefits observed in previous experiments, such as disease and nematode suppression or to encourage root growth, it appears that there would be no negative side effects on harvest juice quality parameters or yield components. 


\section{LITERATURE CITED}

1. Price, S., 2002. Crop Prediction and Adjustment, in Viticulture Extension Newsletter, Oregon State University.

2. Winkler, A. J., J.A. Cook, W.M. Kliewer, and L.A. Lider 1962. General Viticulture: University of California Press.

3. Kennedy, J., 2002. Understanding grape berry development, in Practical Vineyard and Winery. 1-4.

4. Jackson, D. I. and P. B. Lombard, 1993. Environmental and management practices affecting grape composition and wine quality- a review. American Journal of Enology and Viticulture 44(4):409-430.

5. Spayd, S. E., R.L. Wample, R.G. Evans, R.G. Stevens, B.J. Seymour, and C.W. Nagel, 1994. Nitrogen fertilization of White Riesling grapes in Washington: must and wine composition. American Journal of Enology and Viticulture 45(1):34-42.

6. Christensen, L. P., M.L. Bianchi, W.L. Peacock, and D.J. Hirschfelt, 1994. Effect of nitrogen fertilizer timing and rate on inorganic nitrogen status, fruit composition, and yield of grapevines. American Journal of Enology and Viticulture 45(4):377387.

7. Hilbert, G., J.P. Soyer, J. Giraudon, S. Milin and J.P. Gaudillere, 2003. Effects on nitrogen supply on must quality and anthocyanins accumulation in berries of $\mathrm{cv}$. Merlot. Vitis 42(2):69-76.

8. Linsenmeier, A. W., U. Loos, O. Lohnertz, 2008. Must composition and nitrogen uptake in a long-term trial as affected by timing of nitrogen fertilization in a coolclimate Riesling vineyard. American Journal of Enology and Viticulture 59(3):255264.

9. Reynolds, A. G., W.D. Lowrey, and C. De Savigny, 2005. Influence of irrigation and fertigation on fruit composition, vine performance, and water relations of Concord and Niagara grapevines. American Journal of Enology and Viticulture 56(2):110-128.

10. Cabaleiro, C., A. Segura, and J.J. Garcia-Berrioes, 1999. Effects of grapevine leafroll-associated virus 3 on the physiology and must of Vitis vinifera L. cv. Albarino following contamination in the field. American Journal of Enology and Viticulture 50(1):40-44.

11. Lee, J., and R.R. Martin, 2009. Influence of grapevine leafroll associated viruses (GLRaV-2 and -3) on the composition of Oregon Vitis vinifera L. cv. Pinot noir: Phenolics. Food Chemistry 112:889-896.

12. Reynolds, A. G., W.S. Lanterman, and D.A. Wardle, 1997. Yield and berry composition of five Vitis cultivars as affected by Rupestris stem pitting virus. American Journal of Enology and Viticulture 48(4):449-458.

13. Ojeda, H., C Andary, E. Kraeva, A. Carbonneau, and A. Deloire, 2002. Influence of Pre- and Postveraison Water Deficit on Synthesis and Concentration of Skin Phenolic Compounds during berry growth of Vitis vinifera cv. Shiraz. American Journal of Enology and Viticulture 53(4):261-267.

14. Downey, M. O., N. K. Dokoozlian, and M. P. Krstic, 2005. Cultural practice and environmentall impacts on the flavonoid composition of grapes and wine: a review of recent research. American Journal of Enology and Viticulture 57(3):257-268. 
15. Marais, J., F. Calitz, and P.D. Haasbroek, 2000. Relationship between microclimatic data, aroma component concentrations and wine quality parameters in the prediction of Sauvignon blanc wine quality. South African Journal of Enology and Viticulture 22(1):22-26.

16. Walker, R. B., D.H. Blackmore, P.R. Clingeleffer, G.H. Kerridge, E.H. Ruhl, and P.R. Nicholas, 2005. Shiraz berry size in relation to seed number and implications for juice and wine composition. Australian Journal of Grape and Wine Research 11(1):2-8.

17. Vail, M. E., J.A. Wolpert, W.D. Gubler, and M.R. Rademacher, 1998. Effect of cluster tightness on Botrytis bunch rot in six Chardonnay clones. Plant Disease 82(1):107-109.

18. Bravdo, B., Y. Hepner, C. Loinger, S. Cohen, and T. Tabacman, 1985. Effect of crop level and crop load on growth, yield, must and wine composition, and Quality of Cabernet Sauvignon. American Journal of Enology and Viticulture 36(2):125130.

19. Castellarin, S. D., M.A. Matthews, G. Di Gaspero, G. Gambetta, 2007. Water deficits accelerate ripening and induce changes in gene expression regulating flavonoid biosynthesis in grape berries. Planta 227:101-112.

20. Bravdo, B., Y. Hepner, C. Loinger, S. Cohen, and T. Tabacman, 1984. Effect of crop level on growth, yield, and wine quality of a high yielding Carignane vineyard. American Journal of Enology and Viticulture 35(4):247-252.

21. Liu, Z. and D. I. Dickmann, 1996. Effects of water and nitrogen interaction on net photosynthesis, stomatal conductance, and water-use efficiency in two hybrid poplar clones. Physiologia Plantarum 97(3):507-512.

22. Claussen, W. and F. Lenz, 1999. Effect of ammonium or nitrate nutrition on net photosynthesis, growth, and activity of the enzymes nitrate reductase and glutamine synthetase in blueberry, raspberry and strawberry. Plant and Soil 208(1):95-102.

23. Keller, M., M. Kummer, and M. C. Vasconcelos, 2001. Soil nitrogen utilisation for growth and gas exchange by grapevines in response to nitrogen supply and rootstock. Australian Journal of Grape and Wine Research 7(1):2-11.

24. Kliewer, W. M., B.M. Freeman, and C. Hosssom, 1983. Effect of irrigation, crop level, and potassium fertilization on Carignane vines. I. Degree of water stress and effect on growth and yield. American Journal of Enology and Viticulture 34(3):186-196.

25. Keller, M., K.J. Arnink, K.J., and G. Hrazdina, 1998. Interaction of nitrogen availability during bloom and light intensity during veraison. I. Effects of light intensity on grapevine growth, fruit development, and ripening. American Journal of Enology and Viticulture 49(3):333-340.

26. Spayd, S. E., R.L. Wample, R.G. Stevens, R.G. Evans, and A.K. Kawakami, 1993. Nitrogen fertilization of white Riesling in Washington: Effects on petiole nutrient concentration, yield components, and vegetative growth. American Journal of Enology and Viticulture 44(4):378-386.

27. Ben-Tal, Y., 1990. Effects of gibberellins treatments on ripening and berry drop from Thompson Seedless grapes. American Journal of Enology and Viticulture 41(2):142-146. 
28. Gagne, S., K. Esteve, C. Deytieux, S.C. and L. Geny 2004. Influence of abscisic acid in triggering veraison in grape berry skins of Vitis vinifera L. cv. CabernetSauvignon. Vitis 40(1):7-14.

29. Kasinimatis, A. N., F. H. Swanson, J. E.P. Vilas, W. L. Peacock, and G. M. Leavitt, 1979. The relation of bloom-applied gibberellic acid to the yield and quality of Thompson Seedless raisins. American Journal of Enology and Viticulture 30(3):224-226.

30. Koyama, K., K. Sadamatsu, N. Goto-Yamamoto, 2010. Abscisic acid stimulated ripening and gene expression in berry skins of the Cabernet Sauvignon grape. Functional \& Integrative Genomics 10:367-381.

31. Mori, K., 2005. Effects of abscisic acid treatment and night temperatures on anthocyanin composition in Pinot Noir grapes. Vitis 44(4):161-165.

32. Peppi, M. C., M. W. Fidelibus, and N. Dokoozlian, 2006. Abscisic acid application timing and concentration affect firmness, pigmentation, and color of 'Flame Seedless' grapes. HortScience 41(6): 1440-1445.

33. Peppi, M. C., 2008. Application of abscisic acid rapidly upregulated UFGT gene expression and improved color of grape berries. Vitis 47(1):11-14.

34. Peppi, M. C. and M. W. Fidelibus, 2008. Effects of forchlorfenuron and abscisic acid on the quality of 'Flame Seedless' grapes. HortScience 43(1):173-176.

35. Reynolds, A. G., D.A. Wardle, C. Zurowski, and N.E. Looney, 1992. Phenylureas CPPU and Thidiazuron affect yield components, fruit composition, and storage potential of four seedless grape selections. Journal of the American Society of Horticultural Science 117(1):85-89.

36. Cousins, P. and R. K. Streigler. 2005. Grapevines Rootstocks: Current Use, Research, and Application. 2005 Rootstock Symposium. Osage Beach, Missouri: Mid-America Viticulture and Enology Center, Southwest Missouri State University.

37. Bottcher, C., K. Harvey, C.G. Forde, P.K. Boss, and C. Davies, 2011. Auxin treatment of pre-veraison grape (Vitis vinifera $\mathrm{L}$.) berries both delays ripening and increases the synchronicity of sugar accumulation. Australian Journal of Grape and Wine Research 17:1-8.

38. Davies, C., P.K. Boss, and S.P. Robinson, 1997. Treatment of grape berries, a nonclimacteric fruit with a synthetic auxin, retards ripening and alters the expression of developmentally regulated genes. Plant Physiology 115:1155-1161.

39. Inaba, A., M. Ishida and Y. Sobajima, 1976. Changes in endogenous hormone concentrations during berry development in relation to the ripening of Delaware grapes. Journal of the Japanese Society for Horticultural Science 45(3):245-252.

40. Coenen, C. and T. Lomax, 1997. Auxin-cytokinin interactions in higher plants: old problems and new tools. Trends in Plant Science 2(9):351-356.

41. Skoog, F., 1940. Relationships between zinc and auxin in the growth of higher plants. American Journal of Botany 27(10):939-951.

42. Cawthon, D. L. and J. R. Morris, 1982. Relationship of seed number and maturity to berry development, hormonal changes, and uneven ripening of 'Concord' (Vitis labrusca L.) grapes. Journal of the American Society for Horticultural Science 107(6):1099-1104. 
43. Jeong, S. T., N. Goto-Yamamoto, S. Kobayashi, and M. Esaka, 2004. Effects of plant hormones on the accumulation of anthocyanin biosynthetic genes in grape berry genes. Plant Science 167:247-252.

44. Rademacher, W., 2000. Growth retardants: Effects on gibberellin biosynthesis and other metabolic pathways. Annual Review of Plant Physiology and Plant Molecular Biology 51(501-531).

45. Schmiderer, C., 2010. Influence of gibberellins and daminozide on the expression of terpene synthases and on monoterpenes in common sage. Journal of Plant Physiology 167(10):779-786.

46. Weaver, R. J., 1958. Effect of gibberellic acid on fruit set and berry enlargement in seedless grapes of Vitis uinifera. Nature 181:851-852.

47. Harrell, D. C. and L. E. Williams, 1987. The influence of girdling and gibberellic acid application at fruitset on Ruby Seedless and Thompson Seedless grapes. American Journal of Enology and Viticulture 38(2):83-88.

48. Kasinimatis, A. N., F.H. Swanson, and J. E.P. Vilas, 1978. Effects of bloom applied gibberellic acid on soluble solids and berry weight of Thompson Seedless grapes and on raisin grades. American Journal of Enology and Viticulture 29(4):263-266.

49. Sidahmed, O. A. and W. M. Kliewer, 1980. Effects of defoliation, gibberellic acid, and 4-chlorophenoxyacetic acid on growth and composition of Thompson Seedless grape berries. American Journal of Enology and Viticulture 31(2):149-153.

50. Blaha, J., 1963. Influence of gibberellic acid on the grapevine and its fruit in Czechoslovakia. American Journal of Enology and Viticulture 14:161-163.

51. Singh, K., R.J. Weaver, and J.O. Johnson, 1978. Effect of applications of gibberellic acid on berry size, shatter, and texture of Thompson Seedless Grapes. American Journal of Enology and Viticulture 29(4):258-262.

52. Zabadal, T. J. and M. J. Bukovac, 2006. Effect of CPPU on fruit development of selected seedless and seeded grape cultivars. HortScience 41(1):154-157.

53. Wang, Z., B. Huang, S.A. Bonos, and W.A. Meyer. 2004, 2004. Abscisic acid accumulation in relation to drought tolerance in Kentucky bluegrass. HortScience 39(5):1133-1137.

54. Gagne, S., S. Cluzet, J. Merellin, L. Geny, 2011. ABA initiates anthocyanin production in grape cell cultures. Journal of Plant Growth Regulation 30:1-10.

55. Owen, S. J., M.D. Lafond, P. Bowen, C. Bogdanoff, K. Usher, and S.R. Abrams, 2009. Profiles of abscisic acid and its catabolites in developing Merlot grape (Vitis vinifera) berries. American Journal of Enology and Viticulture 60(3):277-284.

56. California Department of Pesticide Regulation. New Active Ingerdients Registered in California During 2010. Accessed Accessed December 4th 2011

57. Barber, S. A., 1995. Soil Nutrient Bioavailability- A Mechanistic Approach 2nd Edition. 2nd ed: John Wiley \& Sons, Inc.

58. Christensen, L. P., A.N. Kasimatis, and F.L. Jensen, 1978. Grapevine nutrition and fertilization in the San Joaquin Valley. Department of Agricultural Sciences, University of California.

59. Marschner, H., 1986. Mineral Nutrition in Higher Plants: Academic Press Inc. .

60. Conradie, W. J., 1980. Seasonal uptake of nutrients by Chenin blanc in sand culture: I. Nitrogen. South African Journal of Enology and Viticulture 1(1):59-65. 
61. Conradie, W. J. and D. Saayman, 1989. Effects of long-term nitrogen, phosphorus, and potassium fertilization on Chenin blanc vines. II. Leaf Analyses and grape composition. American Journal of Enology and Viticulture 2(1):91-98.

62. Christensen, P., 1984. Nutrient level comparisons of leaf petioles and blades in twenty-six grape cultivars over three years (1979 through 1981). American Journal of Enology and Viticulture 35(3):124-133.

63. Neilsen, G. H., D. Neilsen, P. Bowen, C. Bogdanoff, and K. Usher, 2010. Effect of timing, rate, and form of $\mathrm{N}$ fertilization on nutrition, vigor, yield, and berry yeastassimilable $\mathrm{N}$ of grape. American Journal of Enology and Viticulture 61(3):327336.

64. Bell, A. A., C.S. Ough and W.M. Kliewer, 1979. Effects on must and wine composition, rates of fermentation, and wine quality of nitrogen fertilization of Vitis vinifera var. Thompson Seedless grapevines. American Journal of Enology and Viticulture 30(2):124-129.

65. Ruhl, E. H., A.P. Fuda, and M.T. Treeby, 1992. Effect of potassium, magnesium, and nitrogen supply on grape juice composition of Riesling, Chardonnay, and Cabernet Sauvignon vines. Australian Journal of Experimental Agriculture 32(645649).

66. Wolf, T. K. a. R. M. P., 1988. Effects of rootstock and nitrogen fertilization on the growth and yield of Chardonnay grape vines in New York. American Journal of Enology and Viticulture 39(1):29-37.

67. Morlat, R. and R. Symoneaux, 2008. Long-term additions of organic amendments in a Loire Valley vineyard on a calcareous sandy soil. III. Effects on fruit composition and chemical and sensory characteristics of Cabernet franc wines American Journal of Enology and Viticulture 59(4):375-386.

68. Holzapfel, B. P. and M. T. Treeby, 2007. Effects of timing and rate of N supply on leaf nitrogen status, grape yield and juice composition from Shiraz grapevines grafted to one of three different rootstocks. Australian Journal of Grape and Wine Research 13:14-22.

69. Grant, R. S. and M. A. Matthews, 1996. The influence of phosphorus availability, scion, and rootstock on grapevine shoot growth, leaf area, and petiole phosphorus concentration. American Journal of Enology and Viticulture 47(2):217-224.

70. Dundon, C. G. and R. E. Smart, 1984. Effects of water relations on the potassium status of Shiraz vines. American Journal of Enology and Viticulture 35(1):40-45.

71. Bell, S.-J., and Alan Robson, 1999. Effect of nitrogen fertilization on growth, canopy density, and yield of Vitis vinifera L. cv. Cabernet Sauvignon. American Journal of Enology and Viticulture 50(3):351-358.

72. Cook, J. A. and W. M. Kliewer, 1974. Arginine levels in grape canes and fruits as indicators of nitrogen status of vineyards. American Journal of Enology and Viticulture 25(2):111-118.

73. Conradie, W. J., 1981. Seasonal uptake of nutrients by Chenin blanc in sand culture: II. Phosphorus, potassium, calcium and magnesium. South African Journal of Enology and Viticulture 2(1):7-13.

74. Skinner, P. W., J. A. Cook, and M. A. Matthews, 1988. Responses of grapevine cvs Chenin blanc and Chardonnay to phosphorus fertilizer applications under phosphorus-limited soil conditions. Vitis 27(95-109). 
75. Skinner, P. W. a. M. A. M., 1989. Reproductive development in grape (Vitis vinifera L.) under phosphorus-limited conditions. Scientia Horticulturae 38:49-60.

76. Cook, J. A., W. R. Ward, and A. S. Wicks, 1983. Phosphorus deficiency in California vineyards. California Agriculture May-June:16-18.

77. Wolpert, J. A., David R. Smart and Michael Anderson, 2005. Lower petiole potassium concentration at bloom in rootstocks with Vitis berlandieri genetic backgrounds. American Journal of Enology and Viticulture 56(2):163-169.

78. Hale, C. R., 1977. Relation between potassium and the malate and tartrate contents of grape berries. Vitis 16:9-19.

79. Dundon, C. G., R. E. Smart, and M. G. McCarthy, 1984. The effect of potassium fertilizer on must and wine potassium levels of Shiraz grapevines. American Journal of Enology and Viticulture 35(4):200-205.

80. Robinson, J. B., 1992. Viticulture- Volume 2 Practices: Winetitles.

81. Baughman, A. T., E.J. Brown, W. Brummett, J.M. Dramko, J.H. Goldstein, and B.E. Hopper, 2000. California Winemaking Impact Assessment. Masters Thesis. University of California Santa Barbara.

82. Rengel, Z., 2003. Handbook of Soil Acidity: Marcel Dekker, Inc.

83. Cook, A., 1962. Zinc and boron deficiency in California vineyards. Wines and Vines 43:22-26.

84. Peacock, W. L. and L. P. Christensen, 2005. Drip irrigation can effectively apply boron to San Joaquin Valley vineyards. California Agriculture 59(3):188-191.

85. Leckie, J. O. and J. A. Davis, 1979. Copper in the Environment. Part 1: Ecological Cycling, ed. J.O. Nriagu, New York: John Wiley and Sons Inc. .

86. Merz, J. E. and P. B. Moyle, 2006. Salmon wildlife and wine: marine-derived nutrients in human dominated ecosystems of central California. . Ecological Applications 16(3):999-1009.

87. Ceci, L., 1990. Squanto and the Pilgrims. Society May/June:40-44.

88. Neptunes Harvest, 2008. Organic Neptune's Harvest All Natural Fertilizer- Product Brochure.

89. Fernandez-Cornejo, J., C. Greene, R. Penn, and D. Newton, 1988. Organic vegetable production in the U.S.: Certified growers and their practices. American Journal of Alternative Agriculture 13(2):69-78.

90. Abassi, P. A., K. L. Conn, and G. Lazarovits, 2004. Suppression of Rhizoctonia and Pythium damping-off of radish and cucumber seedlings by addition of fish emulsion to peat mix or soil. Canadian Journal of Plant Pathology 26:177-187.

91. Abassi, P. A., 2006. Effect of fish emulsion used a preplanting soil amendment on Verticillium wilt, scab, and tuber yield of potato. Canadian Journal of Plant Pathology 28:509-518.

92. Ndiaye, M., C. F. Yamoah and R.P. Dick, 2000. Fish by-product as a soil amendment for millet and groundnut cropping sytems in Senegal. Biological Agriculture and Horticuture 17:329-338.

93. Emino, E. R., 1981. Effectiveness of fish soluble nutrients as fertilizers on container-grown plants. HortScience 16(3):338.

94. Giotis, C., E. Markelou, A. Theodoropoulo, E. Toufexi, E. Hodson ,P. Shotton, R. Shiel, J. Cooper, and C. Leifert 2009. Effect of soil amendments and biological control agents (BCAs) on soil-borne root diseases caused by Pyrenochaeta 
lycopersici and Verticillium albo-atrum in organic greenhouse production systems. European Journal of Plant Pathology 123:387-400.

95. Havlin, J. L., 1993. Soil Fertility and Fertilizers: An Introduction to Nutrient Management, New Jersey: Prentice-Hall, Inc.

96. Brown, M. A., 2004. The use of marine derived products and soybean meal as fertilizers in organic vegetable production. Masters Thesis. Department of Horticultural Science, North Carolina State University.

97. Tourte, L., R.L. Bugg and C. Shennan, 2000. Foliar-applied seaweed and fish powder no not improve yield and quality of organically grown tomatoes. Biological Agricultural and Horticulture 18:15-27.

98. Miers, D. J., and M.W. Perry, 1986. Organic materials applied as seed treatments or foliar sprays fail to increase grain yield of wheat. Australian Journal of Experimental Agriculture 26:367-373.

99. Aung, L. H. and G.J. Flick, 1980. The influence of fish soluble on growth and fruiting of tomato. HortScience 15(1):32-33.

100. Zemke-White, L. W. and M. Ohno, 1999. World seaweed utilization: an end-ofcentury summary. Journal of Applied Phycology 11:369-376.

101. Villares, R., E. Carral, F. Lorenzana, and E. Lopez Mosquera 2007. Drift seaweed evaluation for fertilizer use in Galiza (Northwest Spain): Tissue elemental characterization and site-sampling differences. Journal of Sustainable Agriculture 31(1):45-60.

102. Haslam, S. F. I., and D.W. Hopkins, 1996. Physical and biological effects of kelp (seaweed) added to soil. Applied Soil Ecology (3):257-261.

103. Verkleij, F. N., 1992. Seaweed extracts in agriculture and horticulture: A review. Biological Agricultural and Horticulture 8(4):309-324.

104. Jennings, R. C. and A. J. McComb, 1969. Cytokinins as endogenous growth regulators in the algae Ecklonia maxima (Phaeophyta) and Hypnea (Rhodophyta). Australian Journal of Biological Sciences 22:621-627.

105. Tay, S. A. B., L.M.S. Palni, and J.K. MacLeod, 1987. Identification of cytokinin glucosides in a seaweed extract. Journal of Plant Growth Regulation 5:133-138.

106. Bentley, J. A., 1960. Plant hormones in marine phytoplankton, zooplankton, and seawater. Journal of the Marine Biology Association of the United Kingdom 39:433-444.

107. Temple, W. D. and A. A. Bomke, 1989. Effects of kelp (Macrocystis integrifolia and Ecklonia maxima) foliar applications on bean crop growth. Plant and Soil 117:85-92.

108. Jennings, R. C. and A. J. McComb, 1967. Gibberellins in the red alga Hypnea musciformis (Wulf.) Lamour. Nature 215:872-873.

109. Mowat, J. A., 1963. Gibberellin-like substances in algae. Nature 200(453-455).

110. Boyer, G. L., and S.S. Dougherty, 1988. Identification of abscisic acid in the seaweed Ascophylum nodosum. Biochemistry 27(5):1521-1522.

111. Blunden, G., S.M. Gordon, G.R. Keysell, 1982. Lysine betaine and other quaternary ammonium compounds from British species of the Laminariales. Journal of Natural Products 45(4):449-451. 
112. Blunden, G., S.M. Gordon, B.E. Smith, and R.L. Fletcher, 1985. Quaternary ammonium compounds in species of the Fucaceae (Phaeophyceae) from Britain. British Phycological Journal 20:105-108.

113. Crouch, L. J., R.P. Beckett, and J. van Staden, 1990. Effect of seaweed concentrate on the growth and mineral nutrition of nutrient-stressed lettuce. Journal of Applied Phycology 2(269-272).

114. Beckett, R. P. and J. V. Staden, 1989. The effect of seaweed concentrate on the growth and yield of potassium stressed wheat. Plant and soil 116:29-36.

115. Card, A., D. Whiting, C. Wilson, and J. Breeder, 2008. Organic fertilizers. Colorado State University Extension Garden Notes 234.

116. Rathore, S. S., D.R. Chaudary, G.N. Boricha, A. Ghosh, B.P. Bhatt, S.T. Zodape, and J.S. Patolia, 2009. Effect of seaweed extract on the growth, yield, and nutrient uptake of soybeans (Glycine max) under rainfed condition. South African Journal of Botany 75:351-355.

117. Chouliaras, V., M. Tasioula, C. Chatzissavvidis, I. Therios, and E. Tsabolatidou, 2009. The effects of a seaweed extract in addition to nitrogen and boron fertilization on productivity, fruit maturation, leaf nutritional status and oil quality of the olive (Olea europaea L.) cultivar Koroneiki. Journal of Science, Food, and Agriculture 89(984-988).

118. Beckett, R. P. and J. V. Staden, 1990. The effect of seaweed concentrate on the uptake of foliar-applied $\mathrm{Cu}, \mathrm{Mn}$, and $\mathrm{Zn}$. South African Journal of Botany 56(3):389-392.

119. Turan, M. and C. Kose, 2004. Seaweed extracts improve copper uptake of grapevine. Acta Agriculturae Scandinavica 54(4):213-220.

120. Mancuso, S., E. Azzarello, S. Mugnai, and X. Briand, 2006. Marine bioactive substances (IPA extract) improve foliar uptake and water stress tolerance in potted Vitis vinifera plants. Advanced Horticultural Science 20(2):156-161.

121. Jeannin, J. C. L., and J.F. Morot-Gaudry, 1991. The Effects of Aqueous Seaweed Sprays on the Growth of Maize. Botanica Marina 34:469-473.

122. Crouch, L. J., and J. van Staden, 1992. Effect of seaweed concentrate on the establishment and yield of greenhouse tomato plants. Journal of Applied Phycology 4:291-296

123. Mooney, P. A., 1985. Effect of seaweed concentrate on the growth of wheat under conditions of water stress. South African Journal of Science 81(632-633).

124. Koo, R. C. J., 1988. Response of citrus to seaweed-based nutrient sprays. Proceedings of the Florida State Horticultural Society 101:26-28.

125. Cassan, L., I. Jeannin, T. Lamaze, and J.F. Morot-Gaudry, 1992. The effect of the Ascophyllum nodosum extract Goemar GA 14 on the growth of spinach. Botanica Marina 35:437-439.

126. Lopez-Mosquera, M. E., 1997. Effects of seaweed on potato yields and soil chemistry. Biological Agricultural and Horticulture 14(199-206).

127. Roussos, P. A., N-K. Denaxa, and T. Damvakaris, 2009. Strawberry fruit quality attributes after application of plant growth stimulating compounds. Scientia Horticulturae 119:138-146. 
128. Abdel-Mawgoud, A. M. R., A.S. Tantaway, M.M. Hafez and H.A.M. Habib 2010. Seaweed extract improves growth, yield and quality of different watermelon hybrids. Research Journal of Agriculture and Biological Sciences 6(2):161-168.

129. Beckett, R. P., A.D.M. Mathegka, and J.Van Staden, Effect of seaweed concentrate on yield of nutrient-stressed tepary bean (Phaseolus acutifolius Gray). Journal of Applied Phycology 6:429-430.

130. Jayaraj, J., A. Wan, M. Rahman, and Z.K. Punja, 2008. Seaweed extract reduces foliar fungal diseases in carrot. Crop Protection 27:1360-1366.

131. Jayaraj, J., J. Norrie, Z.K. Punja, 2010. Commercial extract from the brown seaweed Ascophyllum nodosum reduces fungal diseases in greenhouse cucumber. Journal of Applied Phycology 100(6):1-10.

132. Fornes, F., M. Sanchez-Perales and J.L. Guardiola, 2002. Effect of a seaweed extract on the productivity of 'De Nules' clementine mandarin and navelina orange. Botanica Marina 45:486-489.

133. Norrie, J. and T. Branson, 2002. Marine plant extracts impact on grape yield and quality. Acta Horticulturae 594:315-319.

134. Norrie, J., 2006. Benefits of Ascophyllum nodosum marine-plant extract applications on 'Thompson Seedless' grape production. Acta Horticulturae 727:243-248.

135. Norrie, L. and H. Little, 2010. Commercial extracts of Ascophyllum Nodosum positively affects the yield and quality of table grapes. Unpublished research.

136. Kok, D., E. Bal, S. Celik, C. Ozer, and A. Karauz, 2010. The influences of different seaweed doses on table quality characteristics of cv. Trakya Ilkeren (Vitis vinifera L.). Bulgarian Journal of Agricultural Science 16(4):429-435.

137. Parrado, J., Gilete, M.L.E., Friaza, V., Garcia-Martinez, A., Gonzalez-Miret, M.L., Bautista, J.D. and Heredia, F.J., 2007. Enzymatic vegetable extract with bioactive components: Influence of fertilizer on the colour and anthocyanins of red grapes. Journal of the Science of Food and Agriculture 87:2310-2318.

138. Feibert, E. B. G., C.C. Shock, and L.D. Saunders, 2003. Nonconventional additives leave onion yield and quality unchanged. HortScience 38(3):381-386.

139. Taylor, J. S., K.N. Harker, J.M. Robinson, K.R. Foster, 1990. The effect of seaweed extract containing cytokinin on the growth and yield of barley. Canadian Journal of Plant Science 70:1163-1167.

140. Miers, D. J. and M. W. Perry, 1986. Organic materials applied as seed treatments or foliar sprays fail to increase grain yield of wheat. Australian Journal of Experimental Agriculture 26:367-373.

141. Washington, W. S., S. Engleitner, G Boontjes and N. Shanmuganathan, 1999. Effect of fungicides, seaweed extracts, tea tree oil, and fungal agents on the fruit rot and yield in strawberry. Australian Journal of Experimental Agriculture 39(4):487-494.

142. Zhang, X. and E. H. Ervin, 2004. Cytokinin-containing seaweed and humic acid extracts associated with creeping bentgrass leaf cytokinins and drought resisitance. Crop Science 44:1737-1745.

143. Nelson, W. R. and J. van Staden, 1984. The effect of seaweed concentrate on growth of nutrient-stressed, greenhouse cucumbers. HortScience 19(1):81-82. 
144. Sultana, V., J. Ara, and S. Ehteshamul-Haque, 2008. Suppression of root rotting fungi and root knot nematode of chili by seaweed and Pseudomonas aeruginosa. Journal of Phytopathology 156:390-395.

145. Whapham, C. A., T. Jenkins, G. Blunden, and S.D. Hankins, 1994. The role of seaweed extracts, Ascophyllum nodosum, in the reduction in fecundity of Meloidogyne javanica. Fundamentals of Applied Nematology 17(2):181-183.

146. Jayaraj, J., J. Norrie and P. Zamir, 2010. Commercial extract from the brown seaweed Ascophyllum nodosum reduces fungal diseases in greenhouse cucumber. Journal of Applied Phycology:1-9.

147. Cousins, P. and R. K. Striegler. 2005. Grapevines Rootstocks: Current Use, Research, and Application. 2005 Rootstock Symposium. Osage Beach, Missouri: Mid-America Viticulture and Enology Center, Southwest Missouri State University.

148. Hale, C. R., 1977. Relation between potassium and the malate and tartrate contents of grape berries Vitis 16:9-19.

149. Association of Analytical Chemists, 1980. ed. W. Horwitz, Washington, D.C.

150. Huffman, S.A., and K.A. Barbarick, 1981. Soil nitrate analysis by cadmium reduction. Soil Science and Plant Analysis 12(1):79-89.

151. Allen, S. E., H.M. Grimshaw and J.A. Parkinson, 1974. Chemical Analysis of Ecological Materials, New York: John Wiley and Sons.

152. California Irrigation Management Information Service, 2011. Accessed 12 September 2011. 


\section{APPENDIX NUTRIENT ANALYSIS PROCEDURES}

\section{Dumas Combustion Method (Total \% Leaf N):}

1) After drying plant tissue at $80{ }^{\circ} \mathrm{C}$ for 24 hours, leaf blades are ground into a fine powder (particle size $<250 \mu \mathrm{m}$ ) with a ball mill.

2) $5 \times 9$ tin capsules are filled with powder, weighed $(\mu \mathrm{g})$, and recorded.

3) The leaf samples contained in tin capsules are dropped into a quartz combustion tube with an ambient temperature of $1200{ }^{\circ} \mathrm{C}$.

4) The combusted $\mathrm{N}$ in the form of $\mathrm{N}$ gas $\left(\mathrm{N}_{2}\right)$ and $\mathrm{N}$ oxides is forced through a copper wire reduction column heated at $600^{\circ} \mathrm{C}$. The reduction column removes the oxygen from the $\mathrm{N}$ oxides, converting them into $\mathrm{N}_{2}$.

5) The $\mathrm{N}_{2}$ passes through 2 gas traps to remove water vapor and carbon dioxide.

6) The $\mathrm{N}_{2}$ is channeled into an elemental analyzer, along with an isolated reference stream of Helium.

7) The difference in thermal conductivity is plugged into a linear regression model based on combustion values of known standard to materials to determine the mass of the $\mathrm{N}$.

8) The total $\mathrm{N}$ value from the combustion is divided into the weight of the powder from step 2 to calculate total leaf $\mathrm{N}(\%)$.

\section{Cadmium Reduction Method (ppm petiole $\left.\mathrm{NO}_{3}^{-}\right)$:}

1) Dry petiole samples for 24 hours at $50-55^{\circ} \mathrm{C}$.

2) Grind petiole samples into a fine powder with a ball mill.

3) Prepare $125 \mathrm{ml}$ Erlenmeyer flask for each sample.

4) Prepare color reagent: Combine $50 \mathrm{ml}$ phosphoric acid with $400 \mathrm{ml}$ deionized water. Add $20 \mathrm{~g}$ sulfanilamide and swirl until dissolved. Then add $1 \mathrm{~g} \mathrm{~N}-1-$ naphthylenediamine dihydrochloride and swirl until dissolved. Filter solution with filter paper and set aside.

5) Measure approximately one gram of powdered plant material into each flask and record the weight of the sample.

6) Place $20 \mathrm{ml}$ of $0.1 \mathrm{~N} \mathrm{KCl}$ extraction solution (deionized water containing $0.932 \%$ $\mathrm{KCl}$ ) into each bottle and shake for 15 minutes with a reciprocating shaker at a rate of 250 oscillations per minute.

7) Filter samples into test tubes with filter paper, and set aside the filtrate.

8) Send the filtrate through a copperized cadmium column to reduce the $\mathrm{NO}_{3}{ }^{-}$into nitrite.

9) Collect $15 \mathrm{ml}$ leachate from the cadmium column and add $1 \mathrm{ml}$ of color reagent.

10) Once the solution has developed a red color, analyze the light absorption of the sample solution with an electronic spectrophotometer at a $543 \mathrm{~nm}$ wavelength.

11) Plot the absorbance against a standard nitrate curve based on absorbance values of standard $\mathrm{NO}_{3}{ }^{-}$solutions (y-axis) with known $\mathrm{NO}_{3}{ }^{-}$concentrations (x-axis). The location of the absorbance value of the sample on the y-axis of the standard curve will correspond to a $\mathrm{NO}_{3}{ }^{-}$concentration value on the $\mathrm{x}$-axis. 
12) Take the $\mathrm{NO}_{3}{ }^{-}$concentration value from the $\mathrm{x}$-axis and multiply it by the volume of the sample (leachate + reagent), then divide by the weight of the dried petioles from step 5 to calculate ppm $\mathrm{NO}_{3}{ }^{-}$.

\section{Dry Ash Extraction (\% petiole P, K, Ca, Mg; ppm petiole Zn, Fe, Mn, B, and Cu):}

1) Dry petiole samples for 24 hours at $70{ }^{\circ} \mathrm{C}$.

2) Grind petiole samples into a fine powder with a ball mill.

3) Weigh approximately $0.5 \mathrm{~g}$ of ground petiole material into a crucible, weigh the sample, and record the weight of the sample.

4) In a muffle furnace, gradually heat the plant material to $450{ }^{\circ} \mathrm{C}$ over the course of 90 minutes, then ash for 4 hours and allow to cool.

5) Place $10 \mathrm{ml}$ of extraction acid into crucible, then transfer all contents into extraction vial.

6) Cap and shake extraction vial.

7) Measure the amount of each element with atomic absorption spectrophotometry. Divide that value into the weight of the sample in step 3 to determine $\%$ or ppm of nutrient/dry weight. 